BULLETIN Bulletin hispanique

HISPANIQUE Université Michel de Montaigne Bordeaux

110-1 | 2008

Varia

\title{
¿Un icono nacional? La instrumentalización del Quijote en el espacio escolar en el primer tercio del siglo XX
}

Jean-Louis Guereña

\section{(2) OpenEdition}

Journals

Edición electrónica

URL: https://journals.openedition.org/bulletinhispanique/539

DOI: 10.4000/bulletinhispanique.539

ISSN: $1775-3821$

Editor

Presses universitaires de Bordeaux

\section{Edición impresa}

Fecha de publicación: 1 junio 2008

Paginación: 145-190

ISBN: 978-2-86781-511-9

ISSN: 0007-4640

\section{Referencia electrónica}

Jean-Louis Guereña, «¿Un icono nacional? La instrumentalización del Quijote en el espacio escolar en el primer tercio del siglo XX», Bulletin hispanique [En línea], 110-1 | 2008, Publicado el 05 abril 2012, consultado el 17 septiembre 2021. URL: http://journals.openedition.org/bulletinhispanique/539 ; DOI: https://doi.org/10.4000/bulletinhispanique.539 


\title{
¿Un icono nacional? \\ La instrumentalización \\ del Quijote en el espacio escolar en el primer tercio del siglo XX
}

\author{
JEAN-Louis Guereña \\ CIREMIA, Université François Rabelais, Tours
}

Au début du XXe siècle, et plus spécialement avec la réactivation suscitée à partir de 1905 par l'ensemble des commémorations du troisième centenaire, l'instrumentalisation scolaire du Quichotte sinsère dans ce que nous pouvons qualifier de projet "national» dans un pays alors à la recherche de symboles identitaires.

A principios del siglo XX, y especialmente con la reactivación suscitada a partir de 1905 por el conjunto de las conmemoraciones del tercer centenario, la instrumentalización escolar del Quijote forma parte de lo que podemos calificar de proyecto «nacional» en un pais entonces en buisqueda de simbolos de identidad.

In the early XXth century, starting especially in 1905 with the third centenary celebrations, the instrumentalisation of Quixote in schools was part of what we can call $a$ "national» project, in a country which was then looking for symbols of identity.

Mots-clés : Cervantes - Enseignement primaire - Lecture - Manuels scolaires Nationalisme espagnol.

$B H i$, Tome $110, \mathrm{n}^{\circ} 1$ - juin 2008 - p. 145 à 190. 
$\mathrm{P}$ ASADAs ya las festividades del cuarto centenario de la publicación de la primera parte de la célebre obra cervantina, nos proponemos analizar la recepción en el espacio escolar, y lo que podemos calificar de real instrumentalización por el nacionalismo español a principios del siglo XX - concretamente a partir de la preparación y de la celebración en 1905 del tercer centenario de su publicación ${ }^{1}$-, de la obra sin duda más emblemática y universalmente más conocida de Miguel de Cervantes Saavedra [1547-1616], El ingenioso hidalgo Don Quijote de la Mancha ${ }^{2}$.

¿Podemos referirnos al Quijote como a un verdadero icono nacional, formando parte de las mitologías nacionales y en parte de los estereotipos nacionales? ¿Un auténtico "lugar de memoria» que la historiografía actual, interesada cada vez más en plantear cuestiones relacionadas con las políticas de la identidad y de la memoria, intenta repertoriar y analizar ${ }^{3}$ ? La obra cervantina constituye sin duda, y desde hace tiempo, un elemento insoslayable del panteón cultural y también de la cultura escolar, un real capital cultural simbólico.

Diversas exposiciones recientes, en el marco del cuarto centenario, han tratado precisamente, no sólo de exponer varias muestras significativas de Quijotes escolares, publicados esencialmente en la primera mitad del siglo $\mathrm{XX}$, sino también de mostrar la presencia activa y significativa de la obra

1. Ma Josefa Villanueva Toledo, Evelia Vega González, Los tres Centenarios de Cervantes en el siglo XX. Fuentes documentales en el Archivo General de la Administración, Madrid, Ministerio de Cultura. Dirección General de Libros, Archivos y Bibliotecas, 2005, 157 p.

2. Alejandro Tiana Ferrer, «Los libros de lectura extensiva y desarrollo lector como género didáctico. El Quijote en la escuela. Las gramáticas escolares», en Agustín Escolano Benito (Ed.), Historia ilustrada del libro escolar en España Del Antiguo Régimen a la Segunda República, Madrid, Fundación Germán Sánchez Ruipérez, 1997, pp. 281-284, y «Ediciones infantiles y lectura escolar del Quijote. Una mirada histórica", Revista de Educación, Número Extraordinario 2004 [El Quijote y la educación, ed. por Gabriel Janer Manila], pp. 207-220; Santiago López-Ríos Moreno y José Manuel Herrer Massari, «La polémica del Quijote como libro de lectura escolar en España (1900-1920)», en Giuseppe Grilli (Ed.), Actas del II Congreso Internacional de la Asociación de Cervantistas, Napoli, Istituto Universitario Orientale, 1995, pp. 873-886; Nieves Sánchez Mendieta, «Polémica en torno a una Real Orden quijotesca: ¿es conveniente declarar obligatoria la lectura del Quijote en las escuelas?», en Actas del VIII Coloquio Internacional de la Asociación de Cervantistas, El Toboso, Ediciones Dulcinea del Toboso, 1999, pp. 471-480; Paloma Alfaro Torres y Sandra Sánchez García, «La lectura obligatoria del Quijote en las escuelas: Análisis de las ediciones escolares», en Ángel Gregorio Cano Vela y Juan José Pastor Comín (Eds.), Don Quijote en el aula: la aventura pedagógica, Ciudad Real, Universidad de Castilla La Mancha, 2006, pp. 17-26.

3. Pierre Nora, «Entre Mémoire et Histoire. La problématique des lieux», en Les lieux de mémoire, Paris, Gallimard (Quarto), 1997 [1 $1^{\mathrm{a}}$ ed., 1984], t. I, pp. 23-43. Ver Josefina Cuesta Bustillo (Ed.), Memoria e Historia, Madrid, Marcial Pons (Ayer, n 32), 1998, 246 p. 
cervantina dentro del espacio escolar en la época contemporánea, concretada, por ejemplo, en cuadernos escolares o en diarios de clase ${ }^{4}$.

Dentro de la manualística española, así como dentro de la ingente bibliografía de ediciones de la obra cervantina, el Quijote escolar ocupa indudablemente un espacio aparte 5 . A principios del siglo XX, especialmente con la reactivación suscitada a partir de 1905 por las conmemoraciones del tercer centenario, la instrumentalización escolar del Quijote forma parte de lo que podemos calificar de proyecto "nacional» en un país siempre en búsqueda de símbolos de identidad nacional ${ }^{6}$.

Desde luego, la publicación de ediciones escolares del Quijote ha de relacionarse estrechamente con su función asignada dentro de la escuela como manual de lectura y con la importancia otorgada al aprendizaje de la lectura en la enseñanza primaria, por lo que se desarrolló un largo e intenso debate, dentro y más allá de las propias esferas docentes, acerca de la conveniencia y de la utilidad o no de poner directamente al alcance de los niños el texto mismo del Quijote, aunque fuera naturalmente en una versión un tanto aligerada y adaptada a un público infantil.

4. Ana María Badanelli Rubio, El Quijote en la Escuela, exposición virtual del Centro de Investigación MANES de la UNED (<www:uned.es/manesvirtual>); José María Hernández Díaz, José Antonio Bonilla Hernández, El Quijote en la escuela. Exposición IV centenario, Salamanca, Salamanca 2005, Plaza Mayor de Europa, 2005, 107 p.; Gabriela Ossenbach Sauter (Ed.), El Quijote en las aulas, Madrid, Fundación Francisco Giner de los Ríos, 2005, 30 p.; [Ma Victoria Sotomayor, Ana María Navarrete], Don Quijote para niños, ayer y hoy, Madrid, Ministerio de Cultura, 2005, 103 p.

5. Pilar Egoscozábal Carrasco (Ed.), Catálogo de la colección cervantina de la Biblioteca Nacional. Ediciones del Quijote en castellano, Madrid, Biblioteca Nacional, 2006, pp. 201256; José María Lucía Megías (Ed.), También los niños leen el Quijote (Ediciones infantiles y juveniles en la Biblioteca del Centro de Estudios Cervantinos), Con un estudio de Nieves Sánchez Mendieta, Alcalá de Henares, Centro de Estudios Cervantinos, 2007, 386 p.

6. Javier Blasco, «El Quijote de 1905 (apuntes sobre el quijotismo finisecular)», Anthropos, Madrid, $\mathrm{n}^{\circ}$ 98-99 [Miguel de Cervantes. La invención poética de la novela moderna], 1989, pp. 120-124; Carlos M. Gutiérrez, "Cervantes, un proyecto de modernidad para el Fin de siglo (1880-1905)", Cervantes. Bulletin of the Cervantes Society of America, vol. 19, $\mathrm{n}^{\circ} 1$, 1999, pp. 113-124; María del Mar del Pozo Andrés, Currículum e identidad nacional. Regeneracionismos, nacionalismos y escuela pública (1890-1939), Madrid, Editorial Biblioteca Nueva, 2000, pp. 192-196; María Ángeles Varela Olea, Don Quijote, mitologema nacional (Literatura y politica entre la Septembrina y la II República), Alcalá de Henares, Centro de Estudios Cervantinos, 2003, 149 p. 
EL QUIJOTE, ¿ELEMENTO DE LA “CULTURA ESCOLAR NACIONAL”?

Pieza señera de la literatura en lengua castellana, el Quijote forma parte indudablemente del patrimonio cultural mundial y va a quedar elevado a elemento clave de la cultura escolar «nacional», que ningún escolar en España puede ni debe ignorar. $Y$ desde las filas del «nacionalismo español» dominante en las esferas oficiales y en prácticamente todos los partidos de ámbito nacional a principios del siglo XX (incluyendo a la mayor parte del republicanismo) se utilizó al Quijote para intentar nacionalizar a la población infantil ${ }^{7}$.

El libro de texto, que interesa cada vez más a los historiadores, esencialmente a los historiadores de la educación ${ }^{8}$, va a representar en efecto una ocasión privilegiada de articular las distintas representaciones culturales e ideológicas, el conjunto de las mitologías que fundamentan la construcción nacional y que cabe ofrecer a la población juvenil a título de ejemplos y de modelos a seguir.

A finales del siglo XIX y a principios del XX, no cumplía sin embargo en España la Escuela pública su papel nacionalizador-como tampoco lo cumplía de hecho el servicio militar que presentaba aún numerosas y llamativas desigualdades sociales ${ }^{9}-$ al no poder escolarizar, pese a las obligaciones legales, a todos los jóvenes espańoles y al presentar, en general, una pésima imagen tanto de sus locales como de sus actores, los maestros ${ }^{10}$.

Y poco cambiarían la situación las decisiones simbólicas tomadas desde el poder estatal en cuanto a la denominación de las escuelas públicas de primera enseñanza venidas a llamarse en 1910 «escuelas nacionales» o a favor de la presencia en ellas de la bandera y del escudo «nacionales» desde 1893 y de la

7. Sobre el nacionalismo español, ver José Álvarez Junco, «El nacionalismo español como mito movilizador: cuatro guerras», en Rafael Cruz y Manuel Pérez Ledesma (Eds.), Cultura y movilización en la España contemporánea, Madrid, Alianza Editorial, 1997, pp. 35-67 y Mariano Esteban de Vega, «El nacionalismo español, 1878-1936», en Jean-Louis Guereña (Ed.), Les nationalismes dans l'Espagne contemporaine. Idéologies, mouvements, symboles, Paris, Éditions du Temps («Questions de civilisation»), 2001, pp. 77-94.

8. Jean-Louis Guereña, «Los libros de texto en la historia de la educación en España. ¿Un nuevo campo de investigación?», América a debate. Revista de Ciencias Históricas y Sociales, Morelia (México), no 3, Enero-Junio de 2003, pp. 77-92; Jean-Louis Guereña, Gabriela Ossenbach y María del Mar del Pozo (Eds.), Manuales escolares en España, Portugal y América Latina (Siglos XIX y XX), Madrid, UNED Ediciones (Proyecto MANES), 2005, 501 p.

9. Jean-Louis Guereña, Armée, société et politique dans l'Espagne contemporaine (18081939), Nantes, Éditions du Temps (Synthèse de civilisation espagnole), 2003, pp. 38-45.

10. Jean-Louis Guereña, «Infancia y escolarización», en José María Borrás LLop (Ed.), Historia de la infancia en la España contemporánea 1834-1936, Madrid, Ministerio de Trabajo y Asuntos Sociales-Fundación Germán Sánchez Ruipérez, 1996, pp. 347-458. 
adopción en 1907 de una poesía «saludando a la bandera nacional» que los alumnos habían de recitar diariamente en clase.

En este contexto, ¿qué función podía representar, pues, el libro de texto en la construcción y en la estructuración de la «identidad nacional»? ¿Qué papel y qué significado supuso concretamente la instrumentalización del Quijote en el espacio escolar -sin menoscabar por supuesto el interés y la importancia del texto cervantino- en el marco de la que se produjo en ocasión de las fiestas y conmemoraciones llevadas a cabo durante el tercer centenario ${ }^{11}$ ?:

Se nos ha dicho en todos los tratados de retórica que el Quijote es la cristalización eterna del alma española en su forma idiomática y en su doble fondo idealista y realista, y todos los hombres que se forman del espíritu nacional una idea histórica y literaria, más que geográfica y sociológica, se sienten invenciblemente atraídos al pensamiento de festejar en el libro de Cervantes el símbolo de España ${ }^{12}$.

A partir de comienzos del siglo XX, desde el Ministerio de Instrucción Pública y Bellas Artes creado en 1900 por partición del macro-Ministerio de Fomento ${ }^{13}$, se dispuso en efecto la lectura obligatoria del Quijote en las escuelas, por lo que se desarrolló, o se incentivó al menos, lo que podemos calificar de "subgénero» en la producción de libros de texto para la lectura, el llamado "Quijote escolar», cuyos orígenes eran desde luego anteriores y se remontaban a mediados del siglo XIX.

Por otra parte, no tenemos que olvidar que el Quijote constituía claramente a principios del siglo XX uno de los ejes de la enseñanza secundaria que seguía entonces reservada a una élite (la que posteriormente cursaba estudios universitarios). Buena parte de los ejercicios, tanto los escritos como los orales, del examen de ingreso en los Institutos de segunda enseñanza, tras los estudios de primaria pues, se realizaban en efecto a partir del texto mismo del Quijote, lo que implicaba por lo tanto cierta familiarización de los jóvenes con el texto cervantino al final de los estudios primarios:

11. Carme Riera, El Quijote desde el nacionalismo catalán, en torno al Tercer Centenario, Barcelona, Ediciones Destino (Colección Imago mundi, vol. 68), 2005, 244 p.; Francisco J. Flores Arroyuelo, 1905 Tercer Centenario del Quijote, Murcia, Nausícaä (La rosa profunda), 2006, 202 p.

12. Ramiro de Maeztu, «Ante las fiestas del Quijote», Alma Española, Madrid, Año I, n 6, 13-XII-1903, p. 3.

13. Jean-Louis Guereña, «Estado y Escuela en España. Los orígenes del Ministerio de Instrucción Pública», Educadores, Madrid, vol. 42, n 196, Octubre-Diciembre de 2000, pp. 333-356. 
Para ingresar en los Institutos de segunda enseñanza se necesita acreditar haber cumplido la edad de diez ańos y obtener la aprobación de un examen verificado ante Tribunal compuesto de tres Catedráticos del Instituto.

El ejercicio escrito de este examen consistirá en la escritura al dictado de un pasaje del Quijote y en las operaciones de Aritmética que el Tribunal proponga.

[...] El ejercicio práctico se refiere a las materias siguientes:

[...] Lectura, explicación oral y análisis gramatical de un pasaje del Quijote [... ${ }^{14}$.

HACIA EL TERCER CENTENARIO DE LA PUBLICACIÓN DEL QUIJOTE. LAS INICIATIVAS DE MARIANO DE CAVIA Y DE EDUARDO VINCENTI (I903-I904)

En otoño de 1898, tan sólo unos meses después de la «derrota» sufrida por España ante las tropas estadounidenses en Cuba y Filipinas, el novelista Benito Pérez Galdós [1843-1920] publicaba en el semanario Vida Nueva, dirigido por el periodista Dionisio Pérez [1871-1935] -quien llegó a reivindicar, sin éxito, frente a Mariano de Cavia la paternidad de la idea de la celebración del centenario del Quijote ${ }^{15}$-, dos artículos dedicados a Cervantes en donde afirmaba que, tras la pérdida de las últimas colonias, el Quijote constituía en España el principal objeto de orgullo nacional ${ }^{16}$. Lamentando que sólo se honrase a Cervantes en la capital con una pequeña estatua en la Plaza de las Cortes, dejaba bien claro Galdós que las glorias culturales españolas como Cervantes merecían una mayor atención pero no llegaba entonces a proponer nada en concreto para remediar tal situación.

14. «Real decreto reglamentando los exámenes en los establecimientos de enseñanza oficial», 12-IV-1901, art. 5', en Anuario Legislativo de Instrucción pública correspondiente a 1901 publicado por la Sección de Estadística de Instrucción pública, Madrid, 1902, pp. 275276; «Reglamento de exámenes y grados en las Universidades, Institutos, Escuelas Normales, de Veterinaria y de Comercio», 10-V-1901, art. 5, Ibid., p. 304.

15. «El centenario del Quijote», $A B C$, Madrid, I, n 74, 4-XII-1903.

16. Benito Pérez Galdós, "Cervantes», Vida Nueva, Madrid, I, n² 21, 30-X-1898, s.p. y $\mathrm{n}^{\circ} 22,6-\mathrm{XI}-1898$, s.p. Se trataba en realidad de artículos que ya había publicado anónimamente en La Nación en abril de 1868 (ver Peter B. Goldman, "Galdós and Cervantes: two articles and a fragment", Anales Galdosianos, n ${ }^{\circ}$ VI, 1971, pp. 99-106 y William H. Shoemaker, Los artículos de Galdós en "La Nación»1865-1866, 1868 recogidos, ordenados y dados nuevamente a luz con un estudio preliminar, Madrid, Ínsula, 1972, p. 500). Acerca de la revista Vida Nueva, ver María Pilar Celma Valero, Literatura y Periodismo en las revistas de fin de siglo. Estudio e Índices (1888-1907), Madrid, Ediciones Júcar, 1991, pp. 43-47. 
El tercer centenario iba a representar una ocasión idónea para llevar a cabo o proseguir un proyecto nacionalizador, no sin problemas desde luego, dentro del marco de una conmemoración nacional de gran envergadura (como la que se llevó a cabo tres años más tarde para el primer centenario de la llamada «Guerra de la Independencia» ${ }^{17}$ ), contando en este caso con el apoyo oficial materializado por el nombramiento de una Junta estatal para organizar, impulsar y coordinar el conjunto de festejos y de publicaciones de toda índole dedicados a celebrar la obra cervantina ${ }^{18}$, así como con la colaboración más o menos activa de casi todos los intelectuales del momento, para quienes el Quijote se iba convirtiendo en torno al 98 en una verdadera guía espiritual ${ }^{19}$.

No se trataba desde luego del primer centenario en conmemorarse oficial y públicamente (aunque sí la efeméride de la publicación de una obra literaria). Durante la Restauración, en particular desde el segundo centenario de la muerte de Pedro Calderón de la Barca [1600-1681] celebrado en mayo de 1881 y el cuarto centenario del «descubrimiento» de América por Cristóbal Colón [c. 1451-1506] conmemorado en octubre de $1892^{20}$, se tomó la

17. Ver Javier Moreno Luzón, «Entre el progreso y la virgen del Pilar. La pugna por la memoria en el centenario de la Guerra de la Independencia», Historia y Politica, n ${ }^{\circ} 12$ [Nacionalismo español: las políticas de la memoria], 2004, pp. 41-77. Sobre el tema de las conmemoraciones en general y de las identidades nacionales, ver John R. Gillis (Ed.), Commemorations. The politics of national identity, Princeton, Princeton University Press, 1994, 290 p., y Salvador Claramunt y otros, Las conmemoraciones en la historia, Valladolid, Universidad de Valladolid, 2001, 136 p.

18. Ver E. C. [Emilio Cotarelo], «Bibliografía de los principales escritos publicados con ocasión del tercer centenario del Quijote», Revista de Archivos, Bibliotecas y Museos, Madrid, t. 12, 1905, pp. 403-410 y Miguel Sawa y Pablo Becerra (Eds.), Crónica del Centenario del Don Quijote, Madrid, Establecimiento tipográfico de Antonio Marzo, 1905, 559 p.

19. Ver Paul Descouzis, Cervantes y la generación del 98: la cuarta salida de Don Quijote, Madrid, Ediciones Iberoamericanas, 1970, 158 p. (Unamuno, Azorín y Ganivet), y el prólogo de Alberto Navarro a su edición de Miguel de Unamuno, Vida de Don Quijote y Sancho, Madrid, Cátedra (Letras Hispánicas, 279), 4a ed., 2000, pp. 51-71 («Los escritores» de la «Restauración» y los del «98») (Valera, Menéndez Pelayo, Ramón y Cajal, Azorín, Maeztu, Ortega).

20. Salvador Bernabeu Albert, 1892: el IV centenario del descubrimiento de América en España: coyuntura y conmemoraciones, Madrid, Consejo Superior de Investigaciones Científicas, 1987, 206 p. (ver en particular pp. 31-56 ["España ante el Centenario»]), y L'évolution de l'idée de Découverte de l'Amérique en Espagne et en Amérique Latine. Actes du Colloque «ALMOREAL» d'Orléans, novembre 1988, Le Mans, Université du Maine, 1990, pp. 187-235 («La célébration du IVe centenaire de la Découverte»); Carmen Adams Fernández, La América Distorsionada. Una visión española de finales del Siglo XIX, Oviedo, Universidad de Oviedo, 1999, pp. 57-93. Ver también Juan Sisinio Pérez Garzón, «La creación de la historia de España», en Juan Sisinio Pérez Garzón, Eduardo Manzano Moreno, Ramón López Facal, Aurora Rivière Gómez, La gestión de la memoria. La historia de España al servicio del poder, 
costumbre de celebrar periódicamente magnos festejos cívicos para exaltar las que se suponían ser "glorias nacionales» y fomentar de tal manera la cohesión nacional en torno a tales figuras históricas. Una verdadera fiebre conmemorativa ganó, pues, el país a fines del siglo XIX y principios del XX, lo que también quedó plasmado en la construcción -o su proyecto, al menos- en el espacio urbano de varios monumentos y estatuas conmemorativas dedicadas a recordar y ensalzar a dichas personalidades ${ }^{21}$.

En la organización de tales eventos -más o menos consensuales e ideológicamente marcados en un sentido u otro (no tenía evidentemente el mismo significado ni el mismo público el primer centenario de las Cortes de Cádiz en 1912 que el tercer centenario de la muerte de Santa Teresa en 1882)- colaboraban, en mayor o menor grado, entidades oficiales, asociaciones privadas y, cómo no, la prensa y los principales representantes de un «nacionalismo cultural» ${ }^{22}$.

Precisamente, parece ser que la idea de celebrar el tercer centenario de la publicación del Quijote se fraguó por primera vez en un artículo-pregón -casi un manifiesto de hecho, pero también una programación concreta muy completa, lo que demuestra que se trataba de un proyecto muy preparado y elaborado- publicado a bombo y platillo a finales de 1903 por el periodista aragonés Mariano de Cavia [1855-1920] en las columnas de El Imparcial, el aún influyente diario madrileño, que había tenido anteriormente una activa participación en el centenario de la muerte de Calderón.

Contando con el apoyo de otros redactores del periódico y obviamente de su propietario y ex director, Rafael Gasset [1866-1927] -entonces aún Ministro de Agricultura, Industria, Comercio y Obras Públicas (hasta el 5 de diciembre de 1903, fecha de la dimisión del gobierno de Raimundo Fernández Villaverde) ${ }^{23}$-, el célebre cronista (conocido en particular por sus "Chácharas» $\mathrm{y}$ «Platos del día»), que podía alardear de una dilatada y acreditada experiencia

Barcelona, Editorial Crítica, 2000, pp. 87-95.

21. Ver Carlos Reyero, La escultura conmemorativa en España. La edad de oro del monumento público, 1820-1914, Madrid, Cátedra (Cuadernos Arte 35), 1999, 555 p., Stéphane Michonneau, Barcelona: memòria $i$ identitat. Monuments, conmemoracions $i$ mites, Traducció del francés, Vic, Eumo Editorial (Referències, 36), 2002, 429 p., y Neil McWilliam, "Lieux de mémoire, sites de contestation. Le monument public comme enjeu politique de 1880 à 1914», en Ségolène Le Men y Aline Magnien (Eds.), La statuaire publique au XIXe siècle, Paris, Centre des Monuments Nationaux/Éditions du Patrimoine, 2004, pp. 100-115.

22. Eric Storm, «Las conmemoraciones de héroes nacionales en la España de la Restauración. El centenario de El Greco de 1914», Historia y Política, n ${ }^{\circ} 12$ [Nacionalismo español: las políticas de la memoria], 2004, pp. 79-104.

23. Ver Juan Carlos Sánchez Illán, Prensa y politica en la España de la Restauración. Rafael Gasset y El Imparcial, Madrid, Biblioteca Nueva, 1999, pp. 57-202. 
periodística, instaba a conmemorar debidamente la próxima efeméride cervantina. Expresaba el deseo de que el tercer centenario de la publicación del Quijote fuera «un gran acto de resurgimiento español y de reanimación espiritual» y «la más luminosa y esplendorosa fiesta que jamás ha celebrado pueblo alguno en honor de la mejor gloria de su raza, de su habla y de su alma nacional» ${ }^{24}$.

Mariano de Cavia proponía por lo tanto que, más allá de las festividades oficiales, se tratara de impulsar una gran fiesta popular "para todos los pueblos que comulgan con el noble y laborioso culto de sentir hondo, pensar alto y hablar claro" y que habría de celebrarse por todo el país - no limitándose pues a Madrid, la capital, y a Alcalá de Henares, la ciudad natal de Cervantes- así como del otro lado del Atlántico. También proponía publicar en esa ocasión una edición barata del Quijote "de a dos reales», asequible por lo tanto a la gran mayoría de la población, para que en ningún hogar «donde se hable la lengua castellana, nunca se eche de menos la Biblia del buen humor». Finalmente, reclamaba la erección de un verdadero monumento dedicado al Quijote en la capital, «algo más que [...] el menguado "sujetapapeles" de la plaza de las Cortes». Y llamaba a colaborar conjuntamente en tal empresa que «ha de ser anhelo común a todos los hombres cultos» a los principales políticos de la época, Nicolás Salmerón, Segismundo Moret, Francisco Silvela, José Canalejas, Antonio Maura y Melquíades Álvarez.

La propuesta o el llamamiento de Mariano de Cavia recibió inmediatamente una acogida muy positiva, merced también a las gestiones realizadas paralelamente en la Real Academia Espańola y en el parlamento por otros dos colaboradores prestigiosos del diario, académicos y entonces también diputados, José Ortega Munilla [1856-1922], el director de Los lunes de El Imparcial que había asumido de hecho la dirección del periódico al ser nombrado Ministro de Agricultura su cuñado Rafael Gasset ${ }^{25}$, y el novelista Jacinto Octavio Picón [1852-1923], quien intervino en mayo de 1905 en la

24. Mariano de Cavia, «La celebración del tercer centenario del don Quijote», El Imparcial, Madrid, 2-XII-1903, p. 1. Ver Manuel Ortega y Gasset, El Imparcial. Biografía de un gran periódico español, Prólogo de Juan Pujol, Zaragoza, Librería General, 1956, pp. 202-203, Aurelio Baig Baños, Cavia como cervantista, Madrid, Tipografía de la Revista de Archivos, 1928, 45 p. y Fernando Castán Palomar, Cavia, el polígrafo castizo, Pamplona, Editorial Gómez, s.f. [1956], pp. 77-84.

25. Sobre la labor de Ortega Munilla en El Imparcial, ver Carmen Caffarel Serra, «La imagen de Madrid a través de un periodista del XIX: Ortega Munilla (El Imparcial)", en Ángel Bahamonde Magro y Luis Enrique Otero Carvajal (Eds.), La sociedad madrileña durante la Restauración. 1876-1931, Madrid, Comunidad de Madrid-Alfoz, 1989, vol. II, pp. 279-290. 
Academia de San Fernando sobre "Cervantes y el Quijote» ${ }^{26}$, así como por el poeta pontano Manuel Reina Montilla [1856-1905], diputado liberal por Lucena (Córdoba) ${ }^{27}$.

Tras el artículo de Cavia, las reacciones y propuestas fueron múltiples, en general positivas, a veces pidiendo algo más. Desde la revista Alma Española, se pedía por ejemplo que en el proyectado homenaje «figurase [...] algo que no fuese político, ni académico, ni municipal, ni parlamentario; algo que fuese como una muestra espontánea de simpatía del pueblo libre hacia quien, como Cervantes, salió del pueblo [...]» ${ }^{28}$. Un «joven [...] aficionado a la literatura» según Baroja ${ }^{29}$, Juan Huertas Hervás, el secretario de Rubén Darío en París, afirmaba por su parte que la mejor manera de festejar al autor del Quijote consistiría en la publicación de un Real decreto obligando a todos los españoles de menos de sesenta años a saber leer y escribir. Y fuera de España, también encontró algún eco el llamamiento lanzado por Cavia, como en el caso del escritor francés Guillaume Apollinaire [1880-1918] quien publicó a principios de enero de 1904 un artículo dedicado al centenario del Quijote en la revista francesa L'Européen ${ }^{30}$. La iniciativa tomada por Cavia le valió incluso una propuesta, formulada desde las páginas del diario El Imparcial, para figurar en la Real Academia Española, en la cual acabaría por ingresar en febrero de 1916 pero sin llegar a tomar posesión antes de su muerte.

26. Jacinto Octavio Picón, Solemne sesión pública celebrada el día 9 de mayo de 1905 por la Real Academia de San Fernando para conmemorar el tercer Centenario de la publicación de la primera parte del Quijote. Discurso, Madrid, Est. Tip. Sucesores de Rivadeneyra, 1905, 26 p.; Miguel Sawa y Pablo Becerra, Crónica del Centenario del Don Quijote, op. cit., pp. 173-185.

27. Diario de las Sesiones de Cortes. Congreso de los Diputados, Madrid, $n^{\circ}$ 97, 14-XII1903, pp. 2954-2956; Mariano de Cavia, «El Centenario del “Quijote”. En el Congreso. Consagración oficial del Centenario", El Imparcial, Madrid, 15-XII-1903.

28. «Homenajes», Alma Española, Madrid, I, n 5, 6-XII-1903, p. 6. Sobre Alma Española, ver María Pilar Celma Valero, Literatura y Periodismo en las revistas de fin de siglo, op. cit., pp. 95-102. Existe una reedición en facsímil (Madrid, Ediciones Turner, 1998) precedida de un estudio de Patricia O'Riordan (pp. VII-XIV) y de un índice de la revista (pp. XVXXVI).

29. Pío Baroja, Desde la última vuelta del camino. Memorias. IV. Galería de tipos de la época, Madrid, Biblioteca Nueva, 1947, p. 94. Colaborador en 1890 del Album literario, semanal publicado en Orense, en 1899 y 1900 de Vida Nueva, y en 1913 de Mundial Magazine, la revista publicada en París bajo la dirección literaria de Rubén Darío, Huertas Hervás es autor de la novela corta Agridulce, Madrid, Imprenta de G. Pedraza, 1897, 96 p. y de El primer amor. Novela social, Madrid, Luis Parra, Impresor, 1897, 143 p.

30. Guillaume Apollinaire, "Le troisième centenaire de "Don Quichotte" ", L'Européen, 2-I-1904, recogido en Euvres en prose complètes, t. II, Textes établis, présentés et annotés par Pierre Caizergues et Michel Décaudin, Paris, Éditions Gallimard (Bibliothèque de la Pléiade), 1991, pp. 1187-1190. 
Pero también se oyeron algunas voces contrarias a la celebración del centenario como la del ensayista Ramiro de Maeztu [1874-1936], quien en las páginas de la revista Alma Española, donde ya se había publicado una nota sobre el particular, afirmaba, tan sólo unos días tras el llamamiento de Cavia, que el Quijote no era sino «el libro de los cansados, de los viejos y de los decadentes», idea que ya había expresado en 1901 en un artículo de $L a$ Correspondencia de España ${ }^{31}$ :

Guardemos el Quijote para nuestras fiestas íntimas; pero seamos altruistas ya que nuestra decadencia nos permite serlo, y no pretendamos convertir en libro vital de Espańa ese libro de abatimiento y de amargura ${ }^{32}$.

No obstante, «la opinión pública acogió con gran entusiasmo esa iniciativa», tal como afirmaba Eduardo Vincenti [1857-1924] en marzo de 1904, recordando también que la Real Academia Española, a propuesta de Picón y de Ortega Munilla, «acordó la publicación de una edición popular de la inmortal obra de Cervantes», que "el Gobierno se unió a este movimiento", y que «el Congreso, por la voz elocuente del Sr. Reina, rindió también su homenaje a aquella iniciativa» lanzada por Mariano de Cavia ${ }^{33}$.

En efecto, en la sesión parlamentaria del 14 de diciembre de 1903, tanto el propio Presidente del Consejo de Ministros (Antonio Maura [1853-1925]) como los representantes de los grupos parlamentarios de la oposición liberal (Tirso Rodrigáńez y Sagasta [1853-1935]) y republicana (José Muro y López [1840-1907]) coincidieron en asociarse a la iniciativa de Cavia, defendida en el Congreso por Manuel Reina y por Jacinto Octavio Picón, y en la necesidad, pues, de rendir un homenaje nacional a Cervantes y a su obra ${ }^{34}$. «Esa es una obra nacional, de sentimiento común», afirmó entonces Maura, quien subrayaba que «lo único que falta es organizar y dar forma a estas manifestaciones del sentimiento que ya se exponen tan unánime y honrosamente».

Por lo tanto, al poco tiempo, a principios de enero de 1904, el recién formado gobierno conservador de Antonio Maura -a partir del 5 de diciembre de 1903- decidió en efecto colaborar plenamente en el centenario del Quijote,

31. Ramiro de Maeztu, «El libro de los viejos», La Correspondencia de España, Madrid, 12-V-1901.

32. Ramiro de Maeztu, «Ante las fiestas del Quijote», op. cit., p. 4.

33. Diario de las Sesiones de Cortes. Congreso de los Diputados, Madrid, ${ }^{\circ} 141$, Sesión del 10-III-1904, p. 4323.

34. Diario de las Sesiones de Cortes. Congreso de los Diputados, Madrid, n 97, 14-XII-1903, pp. 2954-2956 
aportando el apoyo estatal a la iniciativa lanzada por Mariano de Cavia y convirtiéndola de hecho en una gran «causa nacional». "Para secundar y ordenar la conmemoración del tercer Centenario de la aparición del Quijote», el Presidente del Gobierno decretó en efecto a principios de enero de 1904 la formación de una Junta para coordinar y apoyar las iniciativas que se llevarían a cabo en dicho marco, pues «aunque la mayor excelencia del homenaje consiste en ser popular, al Gobierno incumbe, no sólo asociarse a él, sino procurar el ordenado concierto de las iniciativas» ${ }^{35}$.

Había, pues, tiempo suficiente para organizar grandiosos festejos que sirvieran el proyecto nacionalizador maurista, evidenciado también, por ejemplo, cuando organizó en ese mismo año de 1904 la visita a la capital catalana, dominada por republicanos y catalanistas, del joven monarca Alfonso XIII [1886-1941], que acababa de subir al poder en 1902:

Apréstanse a conmemorarlo y celebrarlo [el Quijote] muchas gentes, con honrosa espontaneidad, patentizándose de este modo que la santa unidad a quien el amor llama Patria, no sólo funde la diversidad de pueblos, territorios, intereses y anhelos de un día, sino también el patrimonio espiritual atesorado por las generaciones que pasaron, y los alientos vivificadores con que se han de realizar los providenciales destinos colectivos ${ }^{36}$.

Amén de Mariano de Cavia, el único en ser designado nominalmente y a quien se reconocía así oficialmente el papel incitador en el centenario, formaban parte de la Junta nada menos que el propio Presidente del Consejo de Ministros, los Ministros de Estado, de la Guerra, de Marina y de Instrucción pública, representantes de la Real Academia Espańola (Alejandro Pidal y Mon [1846-1913]), de la Academia de Bellas Artes de San Fernando (Emilio Nieto Pérez, Marqués de Guadalerzas), de la Asociación de Escritores y Artistas Españoles (Carlos Luis de Cuenca) y del Ateneo de Madrid (José Echegaray y Eizaguirre [1833-1916], quien recibió ese mismo año de 1904 -en unión del poeta francés Frédéric Mistral [1830-1914]- el Premio Nobel de Literatura), el Director de la Biblioteca Nacional (Marcelino Menéndez y Pelayo [1856-

35. «Real decreto nombrando una Junta para secundar y ordenar la conmemoración del tercer centenario de la aparición del Quijote», 1-I-1904, Gaceta de Madrid, Año CCXLIII, $\mathrm{n}^{\circ}$ 2, 2-I-1904, p. 25. Ver Miguel Sawa y Pablo Becerra, Crónica del Centenario del Quijote, op. cit., pp. 103-105. Sobre el primer gobierno de Maura, ver María Jesús González Hernández, El universo conservador de Antonio Maura. Biografía y proyecto de Estado, Madrid, Biblioteca Nueva, 1997, pp. 61-110.

36. «Real decreto nombrando una Junta para secundar y ordenar la conmemoración del tercer centenario de la aparición del Quijote», op. cit. 
1912]), el Presidente de la Diputación Provincial de Madrid (Justino Bernad), el Alcalde de Madrid (Salvador Bermúdez de Castro y O'Lawlor, Marqués de Lema [1863-1946]; Eduardo Vincenti del 28 de junio de 1905 al 15 de junio de 1906) y un representante del Ayuntamiento de Alcalá de Henares (Lucas del Campo).

El Subsecretario de la Presidencia del Consejo de Ministros actuaría además como secretario de la Junta, que empezó a reunirse por primera vez el 17 de marzo de 1904 en la sede del Ministerio de la Presidencia ${ }^{37}$. En total, la Junta se reunió en pleno en nueve ocasiones hasta el mes de mayo de 1905 . Y no cabe duda de que los constantes cambios gubernamentales afectaron más o menos directamente los trabajos, el orden del día y la composición misma de la Junta.

Por ejemplo, entre noviembre de 1904 y febrero de 1905 o sea en poco más de tres meses, se sucedieron en efecto nada menos que tres Jefes de Gobierno: Antonio Maura, Marcelo Azcárraga y Raimundo Fernández Villaverde. Pero ninguno de ellos llegó a plantear la cuestión de la existencia misma de la Junta y por lo tanto la utilidad de conmemorar oficialmente la publicación del Quijote. El acuerdo era general en este punto. Lo que no estuvo a la altura de las necesidades fue como siempre el presupuesto acordado oficialmente.

En la primera sesión celebrada por la Junta, se decidió nombrar a dos comisiones internas de trabajo, una de «Festejos populares», presidida por José de Echegaray y de la que formaban parte el Marqués de Guadalerzas, Justino Bernad, el Marqués de Lema y Mariano de Cavia (como secretario), y otra de «Fiestas Literarias y Artísticas», presidida por Marcelino Menéndez y Pelayo y que contaba con la presencia de Alejandro Pidal, Lucas del Campo y Carlos Luis de Cuenca (secretario).

En la segunda sesión de la Junta celebrada el $1^{\circ}$ de julio de 1904, se discutieron y aprobaron diversas propuestas expuestas por Carlos Luis de Cuenca, secretario de la Comisión de Fiestas Literarias y Artísticas, entre las cuales figuraban la publicación de una «edición popular», copiosa y económica del Quijote, dirigida por la Real Academia Española, de una "edición abreviada» del Quijote para las clases de literatura de los Institutos de Segunda enseñanza, así como de una "edición aún más abreviada» del Quijote para libro de lectura de las Escuelas de Instrucción primaria. Ambas ediciones abreviadas quedaban en manos de la competencia de la «industria popular».

37. Archivo General de la Administración (Alcalá de Henares), Presidencia, Libro 386 (Libro de Actas de la Junta nombrada para secundar y ordenar la Conmemoración del Tercer Centenario de la Aparición del Quijote). 
En la cuarta sesión de la Junta y última del año 1904, se decidió la incorporación de representantes de las denominadas "corporaciones sociales»: el Duque de Uceda, por el Cuerpo Colegiado de la Nobleza, Eduardo Dato [1856-1921], por el Fomento de las Artes y Mariano Viscasillas, por la Facultad de Filosofía y Letras de la Universidad Central.

Pese a que en abril de 1904 ya señalara Menéndez y Pelayo la dificultad de la preparación del centenario, "por lo improvisado y poco maduro del pensamiento tal como le han formulado sus iniciadores» ${ }^{38}$, buena parte de la prensa ${ }^{39}$, varias instituciones privadas (Ateneos y Círculos por ejemplo) y oficiales (Academias, Universidades, Institutos, Ayuntamientos...) recogieron con entusiasmo la idea de celebrar el centenario de la publicación del Quijote y multiplicaron las iniciativas en tal sentido (sean conferencias, procesiones, descubrimientos de lápidas...).

Aprovechando la conmemoración del centenario, los conservadores -en el poder en 1904 y 1905- y sobre todo los liberales -gobernando del 23 de junio de 1905 al 4 de diciembre de 1906- pretendían convertir a Cervantes y sobre todo a la figura misma de don Quijote en un claro símbolo nacional y también, por supuesto, exaltar el idioma castellano -lo que podríamos calificar de «español nacional»- en particular en el espacio escolar, allí precisamente donde unos años antes el Ministerio de Instrucción Pública y Bellas Artes había tenido que hacer rápidamente marcha atrás con su polémico decreto disponiendo que la enseñanza del catecismo «u otra cualquier materia» se impartiera en todas las escuelas primarias del país en lengua castellana, incluyendo pues a las escuelas en Cataluña, donde seguía siendo práctica habitual el utilizar la lengua propia en la enseñanza del catecismo religioso ${ }^{40}$.

En este marco, una «Comisión de la Prensa profesional de primera enseñanza», presidida por el político liberal y antiguo Director General de Instrucción Pública Eduardo Vincenti y en la cual figuraban varios representantes de la prensa pedagógica -como Godofredo Escribano y Hernández ( $\mathrm{La}$ Enseñanza), Hermenegildo Montes (Gaceta de Instrucción Pública), Andrés

38. Carta de Marcelino Menéndez y Pelayo a Francisco Rodríguez Marín, 18-IV-1904, en Epistolario de Menéndez Pelayo y Rodríguez Marin (1891-1912) publicado con algunas notas breves por este último, Madrid, C. Bermejo, Impresor, 1935, pp. 252-253.

39. Antonio Ayuso Pérez, «La Ilustración Española y Americana ante el Tercer Centenario del Quijote», Espéculo. Revista de estudios literarios, Facultad de Ciencias de la Información de la Universidad Complutense de Madrid, Año XII, n 35, Marzo-Junio 2007, 32 p. (http:// www.ucm.es/info/especulo/numero35/tricente/html)

40. "Real decreto declarando obligatoria la enseñanza del Catecismo en castellano», 21-XI-1902, y «Real Orden sobre la enseñanza del Castellano en las Escuelas», 19-XII-1902, en Anuario Legislativo de Instrucción pública correspondiente a 1902 publicado por la Sección de Estadística de Instrucción pública, Madrid, 1903, pp. 968-970 y 987-988. 
Fernández Ollero (El Magisterio Nacional), Ezequiel Solana [1863-1932] (El Magisterio Español)-, convocó a principios de febrero de 1904 entre el "profesorado de la nación» un concurso de proyectos para celebrar una fiesta "genuinamente nacional y española» de la escuela primaria para honrar a Cervantes y, por lo tanto, para que los niños aprendan a «venerar el santo nombre de la Patria en la celebración de una de sus más legítimas glorias», puesto que «la escuela primaria española [...] no puede dejar de asociarse al acto nobilísimo en que la Patria quiere honrar el claro nombre del más ilustre de sus hijos» ${ }^{41}$.

$\mathrm{Al}$ mismo tiempo, y como diputado liberal por Pontevedra (lo era desde 1886), Eduardo Vincenti presentó el 13 de febrero de 1904 en el Congreso de los diputados una proposición de ley «declarando de lectura obligatoria en las escuelas primarias El Quijote de los niños», «entendiendo [...] que el espíritu nacional informa las páginas de aquel libro, y que una discreta selección de las mismas, acompañadas de nuevas observaciones y brevísimo comentario en relación con la capacidad de la niñez, constituiría el más perdurable recuerdo de la nobilísima solemnidad proyectada» ${ }^{42}$.

Para la realización de tal edición escolar del texto cervantino, que sería publicada a expensas del Ministerio de Instrucción Pública y Bellas Artes, Vincenti fijaba unas bases precisas en su proposición de ley: «discreción» en la selección de los pasajes, «sin que puedan transcribirse [...] conceptos o vocables poco en armonía con la edad de los lectores a quienes se destinan»; "que brille en el texto la mayor pureza», citando en pliego separado las ediciones consultadas y las eventuales variantes; inclusión de «brevísimas notas» "que no sea vulgar repetición de lo ya desechado por la crítica»; «que se pongan de manifiesto al fin de cada capítulo, o al terminar la obra, las varias enseñanzas que para educación y cultura de los niños se derivan de tan peregrina obra»; publicación de una biografía cervantina, «nutrida de datos».

En el transcurso de la discusión parlamentaria, ya en marzo de 1904, volvió Vincenti a definir sus objetivos en su discurso en defensa de su proposición que se enmarcaba claramente dentro de un proyecto nacionalizador que de hecho compartía con muchos. Para que la obra «tenga puesto preferente en la enseñanza de la niñez», era preciso según él «que se publique una edición especial del Quijote con destino a las escuelas», «una edición del Quijote adaptada al

41. "Comisión de la Prensa profesional de primera enseńanza. Al profesorado de la Nación», 7-II-1904, El Magisterio Español, Madrid, Año XXXVIII, n 2761, 13-II-1904, p. 90 .

42. «Proposición de ley del Sr. Vincenti declarando de lectura obligatoria en las escuelas primarias El Quijote de los niños", Diario de las Sesiones de Cortes, Apéndice $9^{\circ}$ al n ${ }^{\circ} 125,13-$ II-1904; Archivo del Congreso de los Diputados (Madrid), Serie General de Expedientes, $n^{\circ} 345-54$. 
cerebro, al corazón, al sentimiento, a la conciencia, siempre digna de respeto, del niño», en la cual «el niño aprenda las maravillas de nuestra lengua en ese libro incomparable entre máximas sublimes y sentencias peregrinas» ${ }^{43}$.

En el corto debate parlamentario verificado entonces, tras Vincenti intervino Manuel Reina Montilla, secundando calurosamente la propuesta de su colega:

Rindamos, pues, nuestra admiración ferviente al príncipe de los escritores españoles, publicando, difundiendo y estableciendo como obligatoria la lectura en la instrucción primaria de El Quijote de los niños [...] ${ }^{44}$.

Pero, a petición del entonces Ministro de Instrucción Pública y Bellas Artes, Lorenzo Domínguez Pascual [1863-1926], quien sugirió llevar la iniciativa a la Junta recién creada para coordinar los actos del centenario, Vincenti aceptó finalmente retirar su proposición de ley, que sería recogida ulteriormente por el Ministro de turno.

\section{EL TERCER CENTENARIO Y EL MINISTERIO DE INSTRUCCIÓN PÚBLICA Y BELLAS ARTES (I905)}

Desde el poder estatal, en una coyuntura de honda crisis política tras los acontecimientos finiseculares, el Quijote y su autor podían servir claramente de fermentos aglutinadores para intentar definir una identidad «nacional» en crisis no sólo por la pérdida de Cuba y de los últimos restos de lo que había constituido un inmenso imperio colonial sino también tras la irrupción directa en la escena política y la consolidación de los nacionalismos periféricos, especialmente el catalán y el vasco.

Por lo tanto, la figura misma de don Quijote -un héroe de ficción y no una persona física, cabe insistir en ello- llegó a plasmarse y a reivindicarse como el emblema de la «nación española», el símbolo mismo de su identidad que todos o casi todos reconocían. Podemos hablar al respecto de un proyecto consensual, de coste relativamente poco elevado además, entre las élites

43. Diario de las Sesiones de Cortes. Congreso de los Diputados, Madrid, n 141, Sesión del 10-III-1904, pp. 4323-4324, y Eduardo Vincenti y Reguera, Política pedagógica (Treinta años de vida parlamentaria). Congreso de los Diputados. Discursos relativos a los presupuestos de Instrucción Pública, mensajes de la Corona, interpelaciones, proposiciones de ley, etc., Madrid, Imprenta de los Hijos de M. G. Hernández, 1916, pp. 341-344.

44. Diario de las Sesiones de Cortes. Congreso de los Diputados, Madrid, $\mathrm{n}^{\circ} 141$, Sesión del 10-III-1904, p. 4324. 
políticas que compartían el poder, procedentes tanto de las filas liberales como de las conservadoras, aunque los liberales se mostraran más activos en el campo simbólico, pero también -como era lo habitual en la administración españolade una dificultad generalizada para llegar al cumplimiento efectivo de las disposiciones tomadas, particularmente visible en el asunto del monumento a Cervantes, que la fuerte inestabilidad política de principios del siglo XX no llega a explicar del todo ${ }^{45}$.

El programa oficial del tercer centenario del Quijote constaba en particular de una exposición bibliográfica de ediciones del Quijote en la Biblioteca Nacional, de una exposición de pinturas de Francisco de Zurbarán [1598-1664], coetáneo de Cervantes, de una emisión filatélica y numismática y también de la organización de suscripciones para construir escuelas públicas ${ }^{46}$. ¿Cuál iba a ser, pues, la actuación concreta en la materia del Ministerio de Instrucción Pública y de los distintos ministros que se sucedieron en el cargo?

Acordado por la Junta oficial constituida a principios de 1904 para organizar el tercer centenario de la publicación del Quijote que «las fiestas y solemnidades» previstas en tal ocasión tengan lugar en los días 7, 8 y 9 de mayo de 1905 -que iban a declararse por cierto días festivos en los centros oficiales de enseñanza ${ }^{47}-$, Juan de La Cierva y Peñafiel [1864-1938], el entonces Ministro de Instrucción Pública y Bellas Artes desde el 27 de enero de 1905 en un gobierno conservador presidido por Raimundo Fernández Villaverde [1848-1905] ${ }^{48}$, dispuso a principios de marzo «que se recomiende a todos los

45. Eric Storm, «El Tercer Centenario del Don Quijote en 1905 y el nacionalismo español», en Intelectuales y nacionalismo, Madrid, Instituto Universitario Ortega y Gasset, 1997, pp. 107-144 (trabajo reproducido en Hispania, Madrid, t. LVIII/2, 1998, pp. 624-654) y La perspectiva del progreso. Pensamiento político en la España del cambio de siglo (1890-1914), Madrid, Biblioteca Nueva, 2001, pp. 295-306; Francisca Soria, «El asociacionismo cultural en la segunda mitad del siglo XIX», en Leonardo Romero Tobar (Ed.), Historia de la literatura española. Siglo XIX (II), Ed. por Víctor García de la Concha, Madrid, Espasa, 1998, pp. 88-89 ( Las nuevas fiestas cívicas»).

46. Catálogo de la exposición celebrada en la Biblioteca Nacional en el tercer centenario de la publicación del Quijote, Madrid, 1905, 94-LV p.; Salvador Viniegra, Museo Nacional de Pintura y Escultura. Catálogo oficial ilustrado de la Exposición de las obras de Francisco de Zurbarán, Madrid, Fototipia e imp. de J. Lacoste, 1905, 36 p.

47. «Real Orden declarando festivos los días dedicados al Centenario del Quijote», 6-V-1905, en Anuario legislativo de Instrucción Pública correspondiente a 1905, Madrid, Sección de Estadística de Instrucción pública de la Subsecretaría del Ministerio, 1906, pp. 218-219.

48. Lo era en realidad desde el 16 de diciembre de 1904 en un Gabinete presidido por el General Azcárraga. Se vió obligado a dimitir el 8 de abril a causa de una huelga de estudiantes. 
Centros docentes de España que el día 8 de mayo citado celebren algún acto literario o artístico para solemnizar dicho centenario»" ${ }^{49}$ :

En las Universidades, Institutos, Escuelas especiales, Escuelas Normales y en las de niños y niñas podrá organizarse ese acto con absoluta independencia y adaptándolo a las condiciones y elementos de cada Establecimiento.

Los Rectores de las diez universidades entonces existentes en España desde 1845, responsables administrativos de otros tantos distritos universitarios, quedaban invitados en dar al respecto «las instrucciones necesarias a los Centros docentes del mismo» "por medio de circulares que publicarán en los Boletines oficiales de todas las provincias de su distrito universitario». Tratándose de una operación oficial, el conjunto de la maquinaria administrativa había de colaborar y «los Gobernadores civiles cuidarán de que se les dé cuenta por todos los Centros docentes de su provincia de las fiestas y solemnidades que hayan organizado, y procurarán obtener datos y fotografías de cuantos festejos se celebren, todo lo cual emitirán en los quince días posteriores a dichas fiestas a este Ministerio, a fin de preparar un resumen de los festejos y actos académicos, literarios, artísticos y científicos dedicados a conmemorar tan importante suceso literario».

Ignoramos el grado de colaboración de tales instancias oficiales, que debería de analizarse concretamente a nivel provincial y local, y no parece que se haya editado -o incluso realizado parcialmente- dicho «resumen", salvo si consideramos como tal la amplia y pormenorizada Crónica del Centenario editada por dos periodistas, Miguel Sawa [1863-1910] -sevillano, hermano del escritor naturalista Alejandro Sawa [1862-1909], redactor de El País y de La Democracia Social, director del semanario satírico Don Quijote (1897-1898) y de La Voz de Galicia ${ }^{50}$ - y Pablo Becerra y Prats [?-1915] -redactor de El Correo y director de los Asilos de San Bernardino. Es verdad que la suscripción a la obra se recomendaba oficialmente a los centros docentes a finales de junio de 1905, considerando que en ella «se hace una relación literaria y gráfica de cuantos actos y festejos se han celebrado en Espańa y el extranjero en honor

49. "Real Orden excitando a los centros docentes a que coadyuven a la mayor brillantez de las fiestas del Centenario del Quijote», 6-III-1905, en Anuario legislativo de Instrucción Pública correspondiente a 1905, op. cit., p. 55.

50. Sobre su obra literaria, ver Allen W. Phillips, En torno a la bohemia madrileña 1890-1925. Testimonios, personajes y obras, Madrid, Celeste Ediciones (Biblioteca Bohemia, 2), 1999, pp. 203-208. 
de Cervantes y de su libro inmortal, así como también de los antecedentes del Centenario»" ${ }^{51}$.

Se organizaron, pues, Juntas Municipales encargadas de la celebración del Centenario, coordinadas por el respectivo Gobernador Civil, y contando con la presencia de personalidades locales del mundo de la cultura y del periodismo, solicitando la participación activa de la población (para iluminar las fachadas de las casas, por ejemplo). También fueron invitados a colaborar la Iglesia y el Ejército. Y no cabe duda de que iban a multiplicarse entonces por toda Espańa, y destacadamente en los centros docentes (incluidos, pues, los de enseñanza primaria) ${ }^{52}$, cantidad de iniciativas y de actos diversos (veladas teatrales ${ }^{53}$, conciertos, desfiles, reparto de premios...) para conmemorar la publicación del Quijote y en las cuales el elemento infantil tuvo un destacado protagonismo ${ }^{54}$. Por ejemplo, en Badajoz, el Ayuntamiento, en colaboración con las escuelas públicas de la ciudad, otorgó un total de cincuenta premios de cinco pesetas para contribuir al centenario ${ }^{55}$.

Pero la conmemoración del centenario no se desarrolló sin debate ni algunas reticencias por parte de algunos sectores, por ejemplo en el seno del Ayuntamiento de Barcelona ${ }^{56}$. Si bien no menos de ciento quince ciudades españolas (amén de doscientas doce hispanoamericanas y treinta y una

51. Miguel Sawa y Pablo Becerra, Crónica del Centenario del Don Quijote, op. cit.; «Real orden disponiendo se recomiende a los Centros docentes de este Ministerio la suscripción a la obra Crónica del Centenario de Don Quijote», 28-VI-1905, Gaceta de Madrid, n 190, 9-VII-1905, p. 110.

52. Dionisio M. Ayuso, Tercer centenario de «El Quijote» Por las escuelas de [...] Oviedo, Oviedo, Est. Tip. La Cruz, 1905, 67 p.; Fiesta celebrada en la Escuela Normal Central de Maestras con motivo del tercer centenario de la publicación del Quijote, Madrid, Imp. del Colegio Nacional de Sordomudos y de Ciegos, 1905, 36 p.; Miguel Sawa y Pablo Becerra, Crónica del Centenario del Don Quijote, op. cit., pp. 277-278.

53. Pilar Vega Rodríguez, «Hasta dentro de cien años: el homenaje del teatro al Tercer Centenario del Quijote» (Ia y II a parte), Espéculo. Revista de estudios literarios, Facultad de Ciencias de la Información de la Universidad Complutense de Madrid, Año XI, n 32, Marzo-Junio 2006, 11 p. y no 33, Julio-Octubre 2006, 24 p. (http://www.ucm.es/info/ especulo/numero32/tricente/html y www.ucm.es/info/especulo/numero33/qpvega2.html)

54. Para los casos de Zaragoza, Barcelona y Extremadura, ver Francisca Soria Andreu, El Ateneo de Zaragoza (1864-1908), Zaragoza, Institución Fernando el Católico, 1993, pp. 235-262, Carme Riera, El Quijote desde el nacionalismo catalán, en torno al Tercer Centenario, op. cit., y Roberto C. Montañés Preira, «Entre el idealismo intelectual y la atonía social: La conmemoración del tercer centenario de El Quijote en Extremadura (1905)», Revista de Estudios Extremeños, Badajoz, t. LXI, n II, Mayo-Agosto 2005, pp. 449-484.

55. «Reparto de premios», Nuevo Diario de Badajoz, 9-V-1905, cit. por Roberto C. Montañés Pereira, «Entre el idealismo intelectual y la atonía social: La conmemoración del tercer centenario de El Quijote en Extremadura (1905)», op. cit., p. 465.

56. Stéphane Michonneau, Barcelona: memòria i identitat, op. cit., p. 196. 
extranjeras) celebraron entonces solemnemente el evento de una manera o de otra ${ }^{57}$, el balance global del centenario ha de matizarse y relativizarse. Ya en la época se manifestó alguna decepción ante lo que habían sido concretamente las conmemoraciones del centenario y destacadamente la parte oficial del mismo en la capital. El Imparcial, sin embargo en el origen de la celebración, o precisamente por ello, no vacilaba en estampar como título de uno de sus artículos «Triste homenaje»:

Después de las últimas desdichas nacionales se presentaba una ocasión en que el alma española podía distenderse con amplia aspiración en los ámbitos nacionales. Iba a celebrarse una fiesta en la cual todos estábamos de acuerdo. No había disidentes, sólo había emulación en el entusiasmo [...]. El Gobierno fracasó, el homenaje parecía organizado por Avellaneda [...]. Mejor fuera que no se hubieran celebrado los festejos. Los que tenían la obligación de organizarlos llevarán sobre sí para siempre la vergüenza del desastre ${ }^{58}$.

A semejantes conclusiones llegaba también el cronista de La Revista Socialista, Matías Gómez Latorre [1849-?], para quien la conmemoración madrileña del centenario del Quijote había quedado «reducida a unos cuantos números de un programa de feria de ciudad de tercer orden, cayendo en el ridículo más espantoso ante otros pueblos que en ocasiones análogas han demostrado saber honrarse a sí mismos enalteciendo dignamente sus más legítimas glorias nacionales» ${ }^{59}$. Y señalaba que la mejor manera de «honrar la memoria del gigante de las letras españolas» hubiera sido el realizar «una copiosísima edición del Quijote para repartirla entre las inmumerables gentes que la desconocen, y además el [...] crear alguna institución de carácter permanente y general, escuelas, universidades populares, algo, en fin, que contribuyera de una manera eficaz a la ilustración del pueblo».

Citemos también a Luis de Vargas quien en el semanario La República de las Letras se preguntaba «si no hubiera sido mejor ahorrar todos estos espectáculos mezquinos, vulgares, necios y asquerosos [...] para difundir un poco de cultura

57. Enciclopedia Universal Ilustrada, Madrid, Espasa-Calpe, t. 12, p. 1379 [art. Cervantes].

58. «Triste homenaje», El Imparcial, Madrid, 10-V-1905, p. 1. Ver también E. Gómez de Baquero, «Crónica literaria. El centenario del Quijote. Lo que ha sido y lo que debió ser», La España Moderna, Madrid, XVII, n 98, junio 1905, pp. 142-151; Fernando Soldevilla, El año político 1905, Madrid, 1906, pp. 147-148; Carmen de Zulueta, Navarro Ledesma, el hombre y su tiempo, Madrid-Barcelona, Alfaguara (Estudios de literatura contemporánea), 1968, pp. 165-192.

59. EMEGEELE [Matías Gómez Latorre], «Crónica», 12-V-1905, La Revista Socialista, Madrid, III, n 58, 16-V-1905, p. 307. 
y gastar este dinero, este tiempo, este esfuerzo en enseñar a leer a un obrero, a un solo obrero, y sobre todo en enseñarle a leer y a sentir el Ingenioso Hidalgo y otros libros tales» ${ }^{60}$.

Si bien el erudito y cervantista Francisco Rodríguez Marín [1855-1943] podía desear a principios de mayo de 1905 «que pase esta bullanga», lamentando "cuánto cervantear o cervantofilear, o farolear, que es lo más cierto, gentes que hasta ahora no se acordaron del nombre de Cervantes» ${ }^{61}$, cabe recordar no obstante que al hilo del centenario se publicaron cantidad de libros o artículos eruditos acerca de Cervantes y su obra, completando y renovando en parte las numerosas lecturas y perspectivas críticas -a menudo tópicas- ya realizadas del Quijote desde su publicación a principios del siglo XVII ${ }^{62}$, y también notables obras literarias relacionadas con el Quijote que interpretaban a su manera, como La vida de Don Quijote y Sancho de Miguel de Unamuno [1864-1936], La ruta de Don Quijote de Azorín [1873-1967] y El Ingenioso Hidalgo Miguel de Cervantes Saavedra de Francisco Navarro Ledesma [1869-1905] ${ }^{63}$.

La decisión de erigir en Madrid (sin precisar entonces la ubicación exacta), por suscripción popular, un monumento a Cervantes, «este inmortal ingenio», hecha pública por el nuevo Ministro de Instrucción Pública y Bellas Artes, el médico -antiguo Director general de Sanidad, cesado por Maura a fines de 1903- Carlos María Cortezo y Prieto [1850-1933], el mismo día 8 de mayo de 1905 en la Gaceta de Madrid-, y por el Rey quien leyó el decreto que acababa de firmar en el curso de un acto solemne celebrado en la Real Academia Española ese mismo día, iba a significar otra ocasión para articular de nuevo un claro discurso nacionalista espańol apropiándose para ello del autor del Quijote y de su obra.

Redactada con sumo lirismo y con la retórica un tanto preciosista al uso, la exposición del decreto resulta altamente significativa al particular (y no por

60. Luis de Vargas, «La vida literaria. El Centenario de Cervantes. Un programa oficial y un libro", La República de las Letras, n 2, 13-V-1905.

61. Carta de Francisco Rodríguez Marín a Marcelino Menéndez y Pelayo, 1-V-1905, en Epistolario de Menéndez Pelayo y Rodriguez Marín, op. cit., p. 270.

62. Anthony Close, La concepción romántica del Quijote [The Romantic Approach to Don Quijote], traducción de Gonzalo G. Djembé, Barcelona, Crítica (Letras de humanidad), 2005 [ed. original inglesa, 1978], 350 p.; Ascensión Rivas Hernández, Lecturas del Quijote (Siglos XVII-XIX), Salamanca, Ediciones Colegio de España (Colección Patio de Escuelas, 2), 1998, 262 p.; François Lopez, «Los Quijotes de la Ilustración», Dieciocho. Hispanic Enlightenment, Charlottesville, Special issue in honor of John H. R. Polt, vol. 22.2, 1999, pp. 247-264; Carlos M. Gutiérrez, "Bibliografía del cervantismo finisecular (1880-1910)», en Cuatro estudios de literatura, Valladolid, Grammalea, 1995, pp. 97-149.

63. Ver Anthony Close, La concepción romántica del Quijote, op. cit., pp. 174-207. 
nada volvió Cortezo a repetirlo en 1926 en el mismo escenario) ${ }^{64}$. La «Patria» (término citado dos veces en el conjunto del texto) y la "Nación española» eran, pues, consideradas como voces totalmente sinónimas (y con mayúscula además), movilizadas sin estado de ánimo por el aparentemente entusiasta Ministro. Éste abandonaba poco tiempo después su cartera, a finales de junio, tras la dimisión de Raimundo Fernández Villaverde, poco tiempo antes de la muerte de éste y de su sustitución al frente del Gobierno por el liberal Eugenio Montero Ríos [1832-1914], afiliándose entonces por cierto al partido liberal.

Aunque la suscripción prevista para la construcción del monumento a Cervantes no se llevara entonces efectivamente a cabo, su principio mismo significaba una voluntad estatal de implicar al conjunto de la comunidad hispana, no sólo madrileńa ni incluso española, en un proyecto claramente nacionalizador en torno al idioma castellano.

Dentro de esta perspectiva, el nombre de Cervantes se puso a las primeras escuelas graduadas construidas a principios del siglo XX en las capitales de provincia ${ }^{65}$. También, dentro del movimiento obrero, que cada vez más se preocupaba por la educación a principios del siglo XX ${ }^{66}$, se movilizó entonces el nombre de Cervantes para bautizar escuelas como en el caso de la Escuela Cervantes fundada en 1903 en el seno del Centro Obrero (socialista) de Alcira (Valencia), y «que era y es mantenida [...] por los afiliados de la organización» ${ }^{67}$.

Pero fue sin duda -y muy lógicamente desde luego- en el campo de la edición escolar donde se manifestó de manera algo más positiva la actuación del Ministerio de Instrucción Pública y Bellas Artes en la coyuntura un tanto eufórica del tercer centenario.

\section{EL MINISTERIO DE INSTRUCCIÓN PÚBLICA Y LAS EDICIONES ESCOLARES DEL QUIJOTE}

La publicación en mayo de 1905 por Eduardo Vincenti, uno de los promotores del centenario cervantino en las escuelas y declarado partidario de la lectura del Quijote en las aulas, de una versión compendiada del Quijote para

64. «Real Decreto disponiendo la erección de un monumento a Cervantes», 8-V-1905, en Anuario legislativo de Instrucción Pública correspondiente a 1905, op. cit., p. 220.

65. José E. Serrano Morales, Tercer Centenario del Quijote. Valencia. Cervantes y el Quijote. Discurso en el acto de la colocación de la primera piedra para la construcción de la Escuela graduada "Cervantes», Valencia, Domenech, 1905, 24 p.

66. Jean-Louis Guereña, «Las Casas del Pueblo y la educación obrera a principios del siglo XX», Hispania, Madrid, vol. LI, n ${ }^{178}$, Mayo-Agosto de 1991, pp. 645-692.

67. "Casas del Pueblo pertenecientes a la Unión General de Trabajadores de España», Boletín de la Unión General de Trabajadores de España, Madrid, V, n 53, mayo de 1933, p. 200. 
las escuelas bajo el título de El libro de las Escuelas ${ }^{68}$, y su rápida aprobación oficial a finales de mayo como libro de texto de lectura a petición del interesado tras el informe correspondiente del Consejo de Instrucción Pública (como lo venía haciendo desde su creación en $1843^{69}$ ), contribuyeron a anclar de manera decisiva el Quijote en el espacio escolar, realizando de hecho lo que él mismo había proyectado desde febrero de 1904 con su proposición de ley, finalmente retirada a instancias del entonces Ministro de Instrucción Pública y Bellas Artes.

En el prólogo a su edición, Vincenti encomiaba altamente «el valor educativo del Quijote», señalando las enseñanzas pedagógicas que encierra el texto y afirmando rotundamente que «si la Biblia es el libro de la Iglesia, el Quijote debiera ser el libro de las escuelas»:

Cuando se identifiquen los niños con estas hojas embalsamadas por el amor a la humanidad [...]; cuando se internen por estas lecciones fundamentales de la experiencia, cuando sus espíritus convivan con estas realidades mundanas, ellos sabrán conducirse en todos los actos sociales, porque multitud de preceptos de urbanidad se enlazan unos a otros en el Quijote como rosarios de virtudes ${ }^{70}$.

Seguía al prólogo una biografía de Cervantes debida a Clemente Cortejón [1842-1911], sacerdote y catedrático de Preceptiva literaria en el Instituto de segunda enseńanza de Barcelona. El texto mismo de Cervantes venía aclarado con notas explicativas sacadas en su mayor parte de estudios cervantinos además de una «carta geográfica de los viajes de Don Quijote y sitios de sus aventuras", siguiendo por lo tanto lógicamente las bases que el propio Vincenti había preconizado en su malograda proposición de ley de febrero de 1904.

El primer reconocimiento oficial a ediciones escolares del Quijote se remonta no obstante a 1856, cuando ya comienza a estructurarse realmente la red escolar en España y a sentirse los efectos de la Ley de Instrucción primaria de 1838 en materia de escolarización, lo que no significa desde luego que no

68. Miguel de Cervantes, El ingenioso Hidalgo Don Quijote de la Mancha. El Libro de las Escuelas. Reducción de la obra inmortal de Cervantes. Reducido y compulsado por D. Eduardo Vincenti, Madrid, Imprenta de los Hijos de M. G. Hernández, 1905, 472 p., 8 láms., 1 mapa. Hubo varias reediciones en 1907 y 1908 (5a edición).

69. Sobre el Consejo de Instrucción pública, ver Bernardo Ceprián Nieto, Del Consejo de Instrucción Pública al Consejo Escolar del Estado. Origen y evolución (1836-1986), Madrid, U.N.E.D. (Aula abierta n ${ }^{\circ} 56$ ), 1991, 582 p.

70. Miguel de Cervantes, El ingenioso Hidalgo Don Quijote de la Mancha. El Libro de las Escuelas, op. cit., pp. 14-15. 
existieran algunos precedentes notables en materia de ediciones escolares del Quijote.

Podemos citar al respecto el Manual alfabético del Quijote, o Colección de pensamientos de Cervantes en su inmortal obra, ordenados con algunas notas por Don M. de R., publicado en 1838 por Mariano de Rementería y Fico, Profesor de la Escuela Normal de Madrid (1830-1840), autor o traductor de varios manuales de urbanidad, con la finalidad de que, al darse "por texto en las escuelas de primeras letras, acostumbraría los tiernos oídos de la niñez a la armonía de nuestra habla, que tanto brilla en todo el texto" ${ }^{71}$. "Que en edad más provecta», proseguía Mariano de Rementería, «hechizará a los jóvenes con sus imágenes e instruirá con sus preceptos y que en toda edad y tiempo podrá ser un verdadero Manual tan útil como ameno».

El principio de uniformidad que rigió en la construcción del sistema educativo español desde los liberales con Mariano José Quintana a la cabeza y su célebre Informe de 1813, significó concretamente en materia de edición escolar un sistema de libertad restringida. Y el mecanismo de las listas de libros de texto «aprobados» (o denegados en su caso) por el Consejo de Instrucción Pública va a orientar desde luego la producción de manuales escolares desde finales de la primera mitad del siglo XIX ${ }^{72}$.

En la circular del 10 de diciembre de 1856 «aprobando varias obras para que puedan servir de texto en las escuelas de Instrucción primaria», figuran en efecto dos ediciones escolares -y por lo tanto abreviadas- del Quijote publicadas aquel año ${ }^{73}$ : una, más barata, para las escuelas de Instrucción primaria propiamente dichas ( $E l$ Quijote de los niños y para el pueblo, abreviado por un entusiasta de su autor Miguel de Cervantes Saavedra, su editor

71. Manual alfabético del Quijote, o Colección de pensamientos de Cervantes en su inmortal obra, ordenados con algunas notas por Don M. de R., Madrid, Imprenta de I. Boix, 1838, Prólogo.

72. Manuel de Puelles Benítez, «Estudio preliminar: Política, legislación y manuales escolares (1812-1939)", en José Luis Villalaín Benito (Ed.), Manuales escolares en España t. I: Legislación (1812-1939), Madrid, Universidad Nacional de Educación a Distancia (Serie «Proyecto Manes»), 1997, pp. 17-70.

73. "Circular, de 10 de diciembre de 1856, aprobando varias obras para que puedan servir de texto en las escuelas de Instrucción primaria», listas $n^{\circ} 32$ ("Obras aprobadas y justipreciadas para la enseñanza en las escuelas de Instrucción primaria») y n ${ }^{\circ} 33$ ("Obras aprobadas y justipreciadas para la enseńanza en las escuelas normales, elementales y superiores de Instrucción primaria»), Colección legislativa de España, Madrid, t. 70, 1856, pp. $402-$ 404; José Luis Villalaín Benito (Ed.), Manuales escolares en España. Tomo II: Libros de texto autorizados y censurados (1833-1874), Madrid, Universidad Nacional de Educación a Distancia, 1999 (Serie «Proyecto Manes»), pp. 355-356. 
D. Nemesio del Campo y Rivas, impreso en Madrid, 1856, a 4 rs. en rústica» ${ }^{74}$ ) y otra, más cara y más extensa, para las Escuelas Normales, o sea para los futuros maestros («El Quijote para todos, abreviado y anotado por un entusiasta de su autor Miguel de Cervantes Saavedra, su editor D. Nemesio del Campo y Rivas, impreso en Madrid, 1856, a 10 rs. en rústica» ${ }^{75}$ ).

Ambas obras, debidas - por lo que se refiere naturalmente a la adaptación del texto cervantino- al historiador Fernando de Castro y Pajares [1814-1874] quien se escudaba bajo la fórmula de «un entusiasta de su autor» ${ }^{76}$, figuran también, lógicamente clasificadas entre los libros de lectura, en la amplia recopilación de libros de texto aprobados realizada por la Dirección General de Instrucción Pública en $1885^{77}$.

En el prólogo al Quijote de los niños y para el pueblo, se explicaba que éste salía al mismo tiempo que El Quijote para todos, «no de cuerpo entero para los que estudian lo que leen, o para los que leen por gusto y pasatiempo, sino en boceto para los que comienzan a deletrear y han de llegar a leer» ${ }^{78}$.

«No son fragmentos sueltos - proseguía Fernando de Castro- tomados de aquí y de allá de la historia del ingenioso hidalgo Don Quijote de la Mancha, sino que aunque muy abreviada es la misma historia seguida con ilación y enlace, ordenada cronológica e históricamente, con su primera y segunda parte, desde la primera salida que de su tierra hizo el ingenioso hidalgo hasta que cayó malo, hizo su testamento y murió en su entero y cabal entendimiento».

A partir de la segunda edición de El Quijote de los niños (con el título ligeramente abreviado, abandonando pues la segunda parte del título de la primera edición «y para el pueblo»), Fernando de Castro incorporaba al texto

74. Miguel de Cervantes Saavedra, El Quijote de los niños y para el pueblo, abreviado por un entusiasta de su autor, Madrid, Imp. de José Rodríguez, 1856, 537 p. La obra conoció varias reediciones en 1861, 1867, 1870, 1873, 1877 y 1885, publicándose en 1897 la octava.

75. El Quijote para todos, abreviado y anotado por un entusiasta de su autor Miguel de Cervantes Saavedra, Madrid, Imprenta de José Rodríguez, 1856, XXXVI-620 p., retrato de Cervantes, grabado por A. Roca, con notas de Fernando de Castro.

76. Fernando de Castro publicará posteriormente Fiesta literaria en honor de Cervantes por la Academia de Conferencias y lecturas públicas de la Universidad el 23 de abril de 1869, Madrid, 1869.

77. «Circular de la Dirección general de Instrucción pública, de 1 de enero de 1885, remitiendo el catálogo de libros y objetos aprobados para texto y uso de las escuelas de primera enseñanza», Colección legislativa de Primera enseñanza (1885), Madrid, Imprenta del Colegio Nacional de Sordomudos y de Ciegos, 1886, pp. 1-55; José Luis Villalaín Benito (Ed.), Manuales escolares en España. Tomo III: Libros de texto autorizados y censurados (18741939), Madrid, Universidad Nacional de Educación a Distancia (Serie «Proyecto Manes»), 2002, pp. 81-147.

78. Miguel de Cervantes Saavedra, El Quijote de los niños y para el pueblo, op. cit., Prólogo. 
unos diez grabados (dibujados por Urrabieta y grabados por Sierra) así como un retrato de Cervantes y una pequeña biografía del mismo, lo que indicaba bien su voluntad de dirigirse exclusivamente a un público infantil con esta edición y ya no también al «pueblo». Y por ello no olvidará incluir en la nueva portada del libro la mención honorífica «declarado de texto para las escuelas por el Consejo de Instrucción Pública».

Con El Quijote para todos, pretendía Fernando de Castro hacer un Quijote accesible a todos, «en término de que llegue a ser un libro de faltriquera que alterne con el devocionario y el libro de confesar», para que "nuestra clase media, nuestros labriegos y artesanos lean algo útil y entretenido", alejándoles de «esa afición frenética de nuestro siglo por la lectura de novelas inmorales e irreligiosas de folletín, o si se quiere, de surtido y de propaganda revolucionaria» ${ }^{79}$.

Desde entonces, y pese a que se publicaran varias ediciones similares en la segunda mitad del siglo XIX (incluyendo reediciones de las anteriores) ${ }^{80}$, ninguna de ellas tuvo sin embargo el honor de figurar entre los libros de texto oficialmente aprobados por el Consejo de Instrucción Pública hasta la versión publicada por Vincenti en $1905^{81}$.

Sean cuales sean los méritos del autor, especializado en cierto modo en los temas educativos desde la tribuna parlamentaria, cabe apuntar que Eduardo Vincenti, casado con una hija de Montero Ríos y antiguo Director General de Instrucción Pública de 1892 a 1895 en lo que era entonces el Ministerio de Fomento, era desde octubre de 1895 -y salvo de marzo de 1900 a marzo de 1902- vocal del Consejo de Instrucción Pública, en donde también figuraba por cierto desde febrero de 1902 Carlos María Cortezo, lo que inclina a pensar en cierta parcialidad del Consejo de Instrucción Pública ${ }^{82}$.

El informe de la Sección primera del Consejo de Instrucción Pública -dedicada a asuntos de Instrucción primaria y del Colegio de sordomudos y ciegos- resulta en efecto particularmente laudativo acerca del trabajo llevado

79. El Quijote para todos, abreviado y anotado por un entusiasta de su autor, op. cit., Prólogo.

80. Citemos El Ingenioso Hidalgo Don Quijote de la Mancha. Arreglado para que sirva de texto de lectura en las escuelas de instrucción primaria por la Propaganda Católica, Madrid, Impreso por Bernardino Cao, 1875, XVI-497 p., un retrato y 3 láms. y El Ingenioso Hidalgo don Quijote de la Mancha arreglado para que sirva de lectura en las escuelas de Instrucción Primaria, por D. Juan Manuel Villen cervantista entusiasta, Sevilla, Librería de José G. Fernández, 1885, 622 p., láms.

81. Según las listas recopiladas por José Luis Villalaín Benito en Manuales escolares en España. Tomo III: Libros de texto autorizados y censurados (1874-1939), op. cit., 546 p.

82. Consejo de Instrucción Pública, Datos de 1874-1906, Madrid, Imprenta del Colegio Nacional de Sordomudos y de ciegos, 1907, pp. 24-25, 32 y 34. 
a cabo por Vincenti, «[...] teniendo en cuenta que representa la reducción y compulsa de nuestra más valiosa joya literaria, hechas con incomparable esmero a fin de que El Quijote no sufra menoscabo en su grandiosidad, para que no pueda decirse que se le ha despojado de aquello que constituye la esencia y la virtualidad de su páginas inmortales estima digno del mayor encomio tan concienzudo trabajo" ${ }^{83}$.

Se trataba, pues, de una versión abreviada del Quijote, en la que se habían excluido algunas novelas insertas -como la del Curioso impertinente- y se habían aligerado algunos pasajes, como la historia de la pastora Marcela. Cabe añadir que el adaptador había tenido a bien regalar «en la época del Centenario del Quijote» 160 ejemplares del libro «con destino a los Centros docentes» y que, a modo de recompensa, una Real Orden del 6 de julio de 1905 firmada por el Ministro de Instrucción Pública y Bellas Artes Andrés Mellado Fernández [1864-1918] disponía, tras los informes remitidos por la Real Academia Española y por la Junta facultativa de Archivos, Bibliotecas y Museos, la adquisición por parte del Ministerio de Instrucción Pública y Bellas Artes de un total de 833 ejemplares de dicha obra, al precio de 3 pesetas el ejemplar, para ser destinados a las bibliotecas públicas del país, "por reunir la cualidad de ser de mérito relevante» ${ }^{84}$.

Tras diversos cambios gubernamentales acaecidos en el segundo semestre del año 1905 y el primero de 1906 -después de Mellado, ocuparon sucesivamente el cargo de Ministro de Instrucción Pública y Bellas Artes Manuel Eguilior y Llaguno, Conde de Albox [1842-1916], Vicente Santamaría de Paredes [1853-1924] y Alejandro San Martín y Satrústegui [1847-1908]-, Amelio Gimeno y Cabañas [1852-1936], titular de la cartera de Instrucción Pública del 6 de julio al 30 de noviembre de 1906 en un gobierno presidido por José López Domínguez [1829-1911], firmaba a finales de noviembre de 1906 una Real orden «disponiendo que los Maestros empleen en los ejercicios de lectura la obra Don Quijote de la Mancha», recogiendo un dictamen de la Sección primera del Consejo de Instrucción pública, en donde figuraba como vimos el autor de la proposición de ley de febrero de $1904^{85}$.

83. "Real orden recomendando El libro de las escuelas para texto de lectura», 24-V-1905, en Anuario legislativo de Instrucción Pública correspondiente a 1905, op. cit., pp. 292-293.

84. "Real orden adquiriendo ejemplares del Libro de las Escuelas», 6-VII-1905, en Anuario legislativo de Instrucción Pública correspondiente a 1905, op. cit., pp. 408-411.

85. «Real orden Disponiendo que los Maestros empleen en los ejercicios de lectura la obra Don Quijote de la Mancha», 28-XI-1906, Gaceta de Madrid, n 340, 6-XII-1906, p. 901 y Anuario legislativo de Instrucción Pública correspondiente a 1906, Madrid, Sección de Estadística de Instrucción pública de la Subsecretaría del Ministerio, 1907, pp. 327-328. 
Tras considerar «la necesidad que las generaciones venideras conozcan el Quijote, cosa que no ha ocurrido con las pasadas ni ocurre con la presente, por lo menos con la extensión debida», y teniendo en cuenta "la virtualidad y [...] la conveniencia de que se les lea en todas las escuelas el Quijote, si bien adaptando su lectura a la capacidad de los niños en la íntima relación de su edad y de su vigor ético, toda vez que la más elemental prudencia aconseja prescindir en la lectura escolar de algunos pasajes libres», el dictamen opinaba "que procede dictar una disposición dirigida a los maestros para que en sus ejercicios de lectura empleen la inmortal obra de Cervantes».

Se recomendaba para ello la versión realizada por Vincenti, «sin que este dictamen implique la obligación por parte de los escolares de adquirir la edición elegida por los maestros, y sí sólo la de que éstos la posean en la forma que hoy poseen los demás libros». No olvidemos en efecto que, siguiendo una tradición anterior, otras ediciones escolares habían visto la luz en 1905 en el marco del tercer centenario como la publicada por la editorial Calleja, con múltiples reediciones posteriores ${ }^{86}$. En el prólogo dirigido «a los señores profesores de primera enseñanza», Saturnino Calleja y Fernández [1853-1915], el fundador de la editorial en 1876, explicaba detenidamente su propósito y el método seguido en la edición del texto cervantino, muy similares en realidad a los de Vincenti ${ }^{87}$.

En 1906, no se trataba realmente de una disposición oficial y obligatoria sino de una mera recomendación en dirección a los maestros que permanecía aún relativamente prudente, escudándose además en el dictamen elaborado por el Consejo de Instrucción pública que la Real orden no hacía más que reproducir. ¿Llegó a aplicarse realmente entonces o siguió letra muerta como el proyecto de un segundo monumento a Cervantes en Madrid?

No conviene olvidarse en efecto, y sin referirnos por supuesto a otras ciudades españolas (como Alcalá de Henares, Alcoy, Valencia y Valladolid), que, tras un primer proyecto en tiempos de José $\mathrm{I}^{\circ}$ o sea durante los años de ocupación francesa en España, se colocó en 1835 -al comienzo, pues, de la regencia de María Cristina- en la madrileña plaza de las Cortes (entonces denominada plaza de Santa Catalina) una relativamente modesta estatua de

86. Ver Julio Ruiz Berrio, Anastasio Martínez Navarro, Carmen Colmenar, Miryam Carreño, La Editorial Calleja, un agente de modernización educativa en la Restauración, Madrid, UNED Ediciones (Serie «Proyecto MANES»), 2002, pp. 168-169.

87. Miguel de Cervantes Saavedra, El Ingenioso Hidalgo Don Quijote de la Mancha. Edición Calleja para escuelas ilustrada con artísticos grabados, Madrid, Casa editorial Calleja, 1905, p. 7. 
Cervantes realizada por Antonio Solá [?-1861], con dos relieves para el pedestal obra de José Piquer [1806-1871] y de la que se mofaban, como vimos, tanto Galdós como Cavia ${ }^{88}$.

\section{HACIA LA LECTURA OBLIGATORIA DEL QUIJOTE EN CLASE (I9I2-I920)}

Seis años después de la publicación del decreto de Amelio Gimeno, Santiago Alba Bonifaz, Ministro de Instrucción Pública y Bellas Artes en un gobierno liberal presidido por José Canalejas y Méndez [1854-1912], volvió precisamente a tomar cartas en el asunto del tan dilatado proyecto de monumento dedicado a Cervantes y al Quijote, reconociendo -no podía hacer otra cosa- en la fecha simbólica del 12 de octubre de 1912 que el decreto del 8 de mayo de 1905, que había decidido la construcción del monumento «costeado por suscripción voluntaria» en la euforia del tercer centenario, no había logrado "positiva eficacia»" ${ }^{89}$.

$\mathrm{Y}$, al mismo tiempo que trataba de activar el concurso de anteproyectos del monumento a Cervantes, el texto volvía sobre la necesidad de que «las generaciones escolares se eduquen desde luego en el conocimiento y en la admiración del prodigio literario, que, traducido a las lenguas todas que los hombres hablan sobre la tierra, constituye el símbolo vivo y perdurable de una grandeza que nadie puede disputarnos».

Entre las doce disposiciones tomadas entonces, amén de la apertura de una «suscripción escolar del monumento a Cervantes» (punto 50) y de la organización de «cursos de conferencias cervantinas» así como de «lecciones de vulgarización popular de igual carácter» (punto $10^{\circ}$ ), se intentaba introducir de nuevo, esta vez con carácter indudablemente más firme que en las anteriores

88. Carlos Reyero, La escultura conmemorativa en España, op. cit., pp. 35 y 130; Enciclopedia Universal Ilustrada, Madrid, Espasa-Calpe, t. 12, p. 1379 [art. Cervantes].

89. «Real orden disponiendo que por la Subsecretaría de este Ministerio se proceda a anunciar, en el término más breve, el concurso de anteproyectos del monumento que para conmemorar la publicación de “El Ingenioso Hidalgo Don Quijote de la Mancha”, se erigirá en Madrid, por suscripción voluntaria, en honor de Miguel de Cervantes Saavedra», 12-X-1912, en Colección Legislativa de España, t. XLV, vol. $2^{\circ}$ de 1912, Madrid, Imprenta de la Revista de Legislación, 1912, pp. 689-692. Curiosamente, el texto no figura en el correspondiente Anuario legislativo de Instrucción pública. Ver también la «Real orden disponiendo se interese del Gobernador del Banco de España el que por dicho Establecimiento de crédito se circulen las órdenes oportunas a todas sus Sucursales para que admitan las cantidades que se entreguen con destino a la suscripción abierta por este Ministerio para la erección de un monumento a Cervantes, y que la cantidad establecida como mínimum para las entregas se reduzca a 50 pesetas», 7-XI-1912, Gaceta de Madrid, n 324, 19-XI-1912, p. 463. 
normativas oficiales pero aún de forma un tanto imprecisa, la lectura del Quijote en las aulas:

Los Maestros nacionales incluirán todos los días, a contar del $1^{\circ}$ de Enero próximo, en sus enseñanzas una dedicada a leer y explicar brevemente trozos de las obras cervantinas más al alcance de los escolares (punto $11^{\circ}$ ).

También, se preveía «la adjudicación de premios a los Maestros y a los alumnos que más se distingan en aquellos cursos» y se pedía a la Real Academia Española informara «en el término más breve, a este Ministerio acerca de la forma, plan de publicación y personas a quienes haya de confiarse la dirección de las dos ediciones del Quijote, una de carácter popular y escolar y otra crítica y erudita» (punto $12^{\circ}$ ).

Cabe apuntar que si bien el Ministerio, siguiendo la opinión del Consejo de Instrucción Pública, había recomendado calurosamente la edición resumida por Vincenti en 1905, otras versiones similares no corrieron la misma suerte, a la espera sin duda de la publicación de aquella edición escolar «oficial» o porque sus autores carecían de los debidos apoyos en el seno del Consejo de Instrucción Pública. Fue así el caso en septiembre de 1916 de la nueva versión compendiada de El ingenioso hidalgo don Quijote de la Mancha publicada por la casa editorial Perlado, Páez y Compañía (Sucesores de Hernando) ${ }^{90}$, y que según el informe cursado por el Consejo de Instrucción Pública (en el cual seguía figurando Eduardo Vincenti) no reunía los requisitos requeridos para este tipo de publicación ${ }^{91}$.

Mientras tanto, la conmemoración del tercer centenario de la muerte de Cervantes que había de celebrarse el 23 de abril de 1916 fue suspendida «indefinidamente» a causa de los acontecimientos desencadenados por la Primera Guerra Mundial, pese a que Espańa no participara directamente en el conflicto bélico ${ }^{92}$. Entre las actividades programadas para el centenario por la

90. Ver Jean-François Botrel, «Nacimiento y auge de una editorial escolar: la Casa Hernando de Madrid (1828-1902)», en Libros, Prensa y Lectura en la España del siglo XIX, Madrid, Fundación Germán Sánchez Ruipérez (Biblioteca del Libro 53), 1993, pp. 387-390.

91. «Real orden negando la declaración de utilidad para servir de texto en las escuelas de primera enseñanza a la obra titulada El ingenioso hidalgo don Quijote de la Mancha (nueva edición compendiada)", 16-IX-1916, Boletín Oficial del Ministerio de Instrucción pública y Bellas Artes, Madrid, n 82, 13-X-1916, pp. 8-9. Ver José Luis Villalaín Benito (Ed.), Manuales escolares en España. Tomo III: Libros de texto autorizados y censurados (1874-1939), op. cit., pp. 327-328.

92. «Real decreto declarando suspendidas indefinidamente todas las fiestas y solemnidades 
Junta nombrada al efecto en octubre de 1914, se encontraban la publicación de varias ediciones del Quijote tal como ya lo preveía la orden de octubre de 1912 - «la una crítica y con comento, tal como hoy lo exige el adelanto de nuestra cultura, y la otra de carácter popular y escolar, con ilustraciones artísticas y notas breves, así históricas como [de] vocabulario y de gramática»y la construcción efectiva (o al menos la puesta en marcha de su proceso) del monumento a Cervantes ya proyectado desde hacía varios años ${ }^{93}$.

El conocido cervantista Francisco Rodríguez Marín ${ }^{94}$, miembro de la Real Academia Española desde $1907^{95}$, Director de la Biblioteca Nacional de 1912 a 1930 y miembro del Consejo de Instrucción Pública desde agosto de 1909, ocupó el cargo de Presidente del Comité Ejecutivo del nuevo y malogrado Centenario (junto con Blanca de los Ríos de Lampérez [1859-1956], Mariano de Cavia, José Gómez Ocaña [1860-1919], José María de Ortega Morejón [1860-?], Norberto González Aurioles, vocales, y Fidel Pérez Mínguez, secretario).

Pese a hallarse canceladas a principios de 1916 las fiestas oficiales de conmemoración del tercer centenario de la muerte de Cervantes, el Ministro de Instrucción Pública Julio Burell [1859-1919] pretendió organizar no obstante una más modesta fiesta escolar en Madrid que iba a consistir en un desfile de los niños de las escuelas públicas de Madrid, portando estandartes, ante la estatua de Cervantes en la plaza de las Cortes ${ }^{96}$.

proyectadas para conmemorar la muerte de Miguel de Cervantes Saavedra», 30-I-1916, Colección Legislativa de España, Madrid, Imprenta de la Revista de Legislación, t. LVI, 1916, pp. 161-163.

93. «Real decreto nombrando una Junta compuesta de los seńores que se mencionan al objeto de preparar y dirigir las solemnidades, fiestas y demás actos con que haya de conmemorarse el tercer centenario de la muerte de D. Miguel de Cervantes Saavedra, y la cual procurará llevar a la práctica, entre otros, los proyectos que se publican», 22-IV-1914, Colección Legislativa de España, Madrid, Imprenta de la Revista de Legislación, t. L, 1914, pp. 485-488. Ver también el «Real decreto disponiendo que para los trabajos preparatorios de las fiestas con que toda España debe conmemorar el tercer centenario de la muerte de Miguel de Cervantes Saavedra, se constituyan desde luego Juntas provinciales y locales en las capitales de provincia y en las cabezas de partido judicial, respectivamente, las cuales estarán constituidas por los elementos que se indican", 9-III-1915, Ibid., t. LIII, 1915, pp. 655-657.

94. Biblioteca Central del C.S.I.C., Madrid, Archivo Francisco Rodríguez Marín, Cajas $\mathrm{n}^{\circ} 20$ y 21.

95. Discursos leidos ante la Real Academia Española en la recepción pública del Excmo. Señor Don Francisco Rodríguez Marin el día 27 de octubre de 1907, Madrid, Tipografía de la Revista de Arch., Bibl. y Museos, 1907, 99 p.

96. «El Centenario de Cervantes. Una fiesta escolar», El Imparcial, Madrid, 18-IV-1916. 
Y, de nuevo, la celebración se tradujo concretamente en un acto patriótico al desfilar los niños vestidos con los colores nacionales, tal como lo recoge la crónica de El Imparcial:

Muchas de las niñas iban vestidas de blanco y llevaban en la cabeza flores de los colores nacionales. La mayoría de los niños lucía, en la solapa de la americana o en la manga de sus limpios vestidos, lazos con los colores rojos y gualda. Todos llevaban su ramo de flores, olorosas y fragantes, recién cogidas, para ofrenderlas al genio, al orgullo de la patria, al que creó aquel maravilloso loco y aquel zafio portentoso, cuyos regocijadores episodios les hicieron reír a mandíbula batiente al leerlos en la escuela ${ }^{97}$.

También podemos aludir en este contexto a la campaña periodística pidiendo la realización de una película española sobre el Quijote (las dos primeras, rodadas respectivamente en 1904 y en 1911, eran extranjeras), costeada por el Estado para garantizar su carácter «oficial» y que pudiera ser exhibida ante jóvenes alumnos ${ }^{98}$.

El papel oficial desempeñado por Rodríguez Marín de cara a homenajear a Cervantes no acabó en 1916 tras la cancelación de la conmemoración del tercer centenario de la muerte del autor del Quijote. En enero de 1920 se le encomendó el presidir el Comité al Monumento a Cervantes del que también formaban parte el Duque de Alba (Jacobo Fitz-James Stuart y Falcó) [18781953], Jacinto Octavio Picón (sustituido tras su defunción en 1926 por Carlos María Cortezo y José Ventura de Cerragería), Luis Landecho y Urries, José María de Ortega Morejón y Francisco Belda ${ }^{99}$. En octubre de 1924, se les unieron los hermanos Serafín [1871-1938] y Joaquín Álvarez Quintero [1873-1944], ambos académicos ${ }^{100}$.

97. «La fiesta de los niños», El Imparcial, Madrid, 24-IV-1916.

98. J. Solá Guardiola, «Cervantes y el cinematógrafo», Mundo Gráfico, Madrid, n 216, 15-XII-1915, s.p.

99. «Real decreto encargando al Comité nombrado por Real orden de 12 de Enero próximo pasado para fomento y organización de la suscripción para la erección del monumento a Cervantes, de la aplicación de los fondos recaudados y de la dirección de las obras; disponiendo que dicho organismo se designe con el nombre de Comité del Monumento a Cervantes, tenga carácter oficial, dependa de esta Presidencia y que la cuenta corriente abierta en el Banco de España se ponga a nombre del referido Comité», 5-II-1920, Gaceta de Madrid, $\mathrm{n}^{\circ} 37,6-$ II-1920, pp. 434-435.

100. «Real orden disponiendo formen parte del «Comité Ejecutivo del Monumento a Cervantes» D. Serafín y D. Joaquín Álvarez Quintero, Académicos de la Real Academia Española», 9-X-1924, Gaceta de Madrid, n 288, 14-X-1924, pp. 247-248. 
Pero el monumento, proyectado desde 1905, iniciado en 1926, sólo vería la luz efectivamente y de forma parcial en 1930, situado en la emblemática Plaza de España de la capital, tras adjudicarse el proyecto definitivo en 1915, en ocasión del tercer centenario de la publicación de la segunda parte del Quijote, al arquitecto Rafael Martínez y Zapatero [?-1936] y al escultor Lorenzo Coullaut Valera [1876-1932] en un concurso reñido y controvertido (se presentaron, en efecto, 53 anteproyectos) ${ }^{101}$. Suspendidas las obras tras el final de la dictadura primoriverista y fallecido el escultor en 1932, sólo se concluyó definitivamente el monumento en 1957 y 1960 por su hijo, Federico Coullaut-Valera Mendigutía [1912-1989] ${ }^{102}$. A Lorenzo Coullaut Valera ya se debía la lápida conmemorativa del primer centenario de la publicación de la edición príncipe del Quijote, situada en el lugar que ocupó en Madrid la imprenta de Juan de la Cuesta ${ }^{103}$.

En la exposición del decreto de 29 de marzo de 1915 se definían por fin las bases concretas a las cuales debía de sujetarse el proyecto de monumento dedicado al autor del Quijote "porque su labor refleja lo más noble del espíritu nacional» $\mathrm{y}$ "porque llevó el idioma a tan alto grado de esplendor, que por él se llama en el mundo entero al castellano la lengua de Cervantes» ${ }^{104}$. El monumento debía ser emplazado en la madrileńa Plaza de España, como remate artístico y simbólico de la misma, el nuevo espacio de sociabilidad

101. «Real orden relativa a la concesión de premios y recompensas a los autores que se mencionan de los anteproyectos presentados al concurso abierto para erigir en esta Corte un monumento a Cervantes», 25-X-1915, Gaceta de Madrid, n 309, 5-XI-1905, p. 264; Rafael Martínez y Zapatero Arquitecto, Lorenzo Coullaut Valera Escultor, Anteproyecto de Monumento a Miguel de Cervantes Saavedra, Madrid, Imp. Alemana, 1915, 6 p.; Rafael Martínez y Zapatero Arquitecto, Lorenzo Coullaut Valera Escultor, Proyecto de Monumento a Miguel de Cervantes Saavedra, Madrid, Raoul Péant, s.f. [1916], 12 p.

102. Ver $\mathrm{M}^{\mathrm{a}}$ del Socorro Salvador Prieto, La escultura monumental en Madrid. Calles, plazas y jardines públicos, 1875-1936, Madrid, Editorial Alpuerto, 1990, pp. 458-471 y «El monumento a Cervantes en la plaza de España», en Cinco siglos de arte en Madrid, siglos $X V-X X$, Madrid, Alpuerto, 1991, pp. 153-162; Juan José Martín González, El monumento conmemorativo en España 1875-1975, Valladolid, Universidad de Valladolid (Arte y Arqueología, 12), 1996, pp. 114-116; Teresa Lavalle, «El largo proceso constructivo del monumento a Cervantes en Madrid", Academia. Boletín de la Real Academia de Bellas Artes de San Fernando, Madrid, n 81, $2^{\circ}$ sem. 1995, pp. 433-447; José María Gajate García, La obra escultórica de Lorenzo y Federico Coullaut-Valera en Madrid, Madrid, Safel Editores, 1997, pp. 79-93 y 136-138.

103. $\mathrm{M}^{\mathrm{a}} \mathrm{del}$ Socorro Salvador Prieto, La escultura monumental en Madrid, op. cit., pp. 225231 y José María Gajate García, op. cit., pp. 119-121.

104. Real decreto "abriendo un concurso de anteproyectos para la creación de un monumento a Miguel de Cervantes Saavedra en la plaza de Espańa, de esta Corte», 29-III-1915, Gaceta de Madrid, n 89, 30-III-1915, p. 936. 
abierto en los terrenos ocupados hasta entonces por la Plaza de San Marcial y el cuartel de San Gil dentro de las transformaciones urbanas relacionadas con el nuevo eje de la Gran Vía, sólo terminada en su totalidad en 1931.

Pero el monumento -y, de forma más general, el homenaje a Cervantesdebía ser el asunto de toda España y no sólo de Madrid. Para contribuir a la suscripción destinada a erigir el monumento a Cervantes, prevista en los decretos de octubre de 1912 y de marzo de 1915, y asimismo estimular entre los niños «el sentimiento de admiración por el inmortal autor del Quijote», se organizaron diversas fiestas en España como unas «veladas patrióticas» celebradas en enero de 1913 en Noreña (Asturias) por el maestro Jacinto Ramos Martínez, contando con el apoyo de las autoridades municipales, y reseñadas en la prensa gráfica de la época ${ }^{105}$.

Pero en enero de 1920 el resultado de la suscripción distaba aún mucho de las expectativas y de las necesidades, pues sólo se había recaudado en la cuenta abierta en el Banco de Espańa para tal objeto la cantidad de 129.357,21 pesetas cuando el presupuesto máximo de las obras fijado en marzo de 1915 se elevaba a un millón de pesetas ${ }^{106}$. Todavía en 1926 , se intentaba fomentar la «suscripción nacional» para el monumento a Cervantes y así "saldar la deuda de honor que la raza española tiene contraída con su más esclarecido representante» ${ }^{107}$.

Y en un acto celebrado ante la Comisión organizadora del monumento en la Real Academia Española en mayo de 1926 y presidido por el Rey Alfonso XIII en persona, el que fue ministro de Instrucción Pública y Bellas Artes en 1905, Carlos Cortezo, entonces Presidente del Consejo de Estado, pronunció un discurso «para recordar la deuda de agradecimiento, de justicia y de patriotismo que tenemos contraída con Miguel de Cervantes Saavedra», recordando la firma hacía 21 años del decreto "por el cual se imponía la realización casi inmediata

105. «En honor de Cervantes», Mundo Gráfico, Madrid, n 66, 29-I-1913, s.p., cit. por María del Mar del Pozo Andrés, Currículum e identidad nacional, op. cit., pp. 195-196.

106. «Real orden disponiendo que por los señores que se mencionan se constituya un Comité para fomento y organización de la suscripción voluntaria abierta por el Real decreto de 8 de Mayo de 1905, entre los pueblos que tienen el castellano por lengua nacional, para la creación en la plaza de España, de Madrid, del monumento a Cervantes, a que se refiere el Real decreto de 5 de Marzo de 1915», 12-I-1920, Gaceta de Madrid, n 14, 14-I-1920, p. 149.

107. «Real orden circular disponiendo que por los Gobernadores civiles se constituyan Juntas formadas por las personas que se indican, con el fin de fomentar la suscripción nacional iniciada para erigir en esta Corte un monumento a Cervantes», 27-V-1926, Gaceta de Madrid, n 149, 29-V-1926, pp. 1178-1179. 
del pensamiento de representar, en una obra escultórica, el entusiasmo del alma española por el genio de Cervantes $[\ldots]{ }^{108}$.

"Cuando menos nosotros», concluía Cortezo, «los españoles de nación y de raza, los idealistas de todos los pueblos, debemos procurar que todos vean nuestro entusiasmo materialmente cristalizado y plasmado en un monumento digno de Cervantes».

Finalmente, el asunto de la suscripción pública fue resuelto de manera autoritaria. En diciembre de 1927 y en enero de 1928, se llegó para tal fin a la cesión, más o menos voluntaria, del $1 \%$ del sueldo de un mes de los funcionarios civiles y militares, pues «todo español debe a las obras del inmortal Cervantes, sobre todo al libro insuperable del «Quijote», momentos de suprema emoción y un íntimo orgullo nacional, que ahora se ofrece ocasión propicia de compensar, contribuyendo con un modesto óbolo a la construcción del monumento» ${ }^{109}$.

En cuanto a la presencia concreta del Quijote en las aulas, tras la crisis de 1917 y sus consecuencias políticas, el Ministro de Instrucción Pública y Bellas Artes Natalio Rivas Santiago [1856-1958] volvía sobre el tema en marzo de 1920 declarando taxativamente la obligatoriedad de la lectura cotidiana del Quijote «en todas las Escuelas Nacionales establecidas en territorio español», precisando además concretamente el horario y la forma de la misma ${ }^{110}$ :

Artículo $1^{\circ}$ Se declara obligatoria la lectura de El Ingenioso Hidalgo Don Quijote de la Mancha, de Miguel de Cervantes Saavedra, en todas las Escuelas Nacionales establecidas en territorio espańol.

108. Carlos María Cortezo, El monumento a Cervantes. Notas taquigráficas del discurso del Excmo. Sr. D. -- ante la Comisión organizadora del monumento, presidida por S.M. el Rey, 8 de mayo de 1905-4 de mayo de 1926, Madrid, Imprenta del Sucesor de Enrique Teodoro, 1926, $19 \mathrm{p}$.

109. «Real orden, circular, invitando a todos los funcionarios del Estado, Provincias y Municipios, Empresas bancarias o industriales y Clases pasivas y similares, a ceder el 1 por 100 del haber mensual del mes de Enero próximo, así como a las entidades particulares que quieran participar en la aportación para conribuir a la erección del Monumento a Cervantes», 28-XII-1927, Gaceta de Madrid, n 364, 30-XII-1927, p. 1983. Ver también la «Real orden, circular, disponiendo que por los respectivos Habilitados de los funcionarios civiles y militares se proceda a ingresar la cantidad a que asciende el 1 por 100 de la suscripción para el monumento a Cervantes», 19-I-1928, Ibid., n² 25, 25-I-1928, pp. 677-678.

110. «Real decreto declarando obligatoria la lectura de "El Ingenioso Hidalgo Don Quijote de la Mancha", de Miguel de Cervantes Saavedra, en todas las Escuelas Nacionales establecidas en territorio español», 6-III-1920, Gaceta de Madrid, Año CCLX, t. I, n 67, 7-III-1920, pp. 873-874, y Colección legislativa de Instrucción pública.-Año de 1920, Madrid, Talleres del Instituto Geográfico y Estadístico, 1921, pp. 140-142. 
Art. $2^{\circ}$ A dicha lectura se dedicará cada día laborable, el primer cuarto de hora de clase, terminado el cual, el Maestro explicará a sus alumnos, con brevedad y en términos apropiados para su inteligencia, la significación e importancia del pasaje o pasajes leídos.

Pero como el artículo $3^{\circ}$ del mismo decreto establecía que «a fin de dotar a las Escuelas Nacionales del material necesario para dar cumplimiento a lo antedicho, se publicará una numerosa edición abreviada del Quijote, cuya preparación estará a cargo, conjuntamente, del Director de la Biblioteca Nacional, un Académico que de su seno designe la Real Academia Espańola y el Catedrático de Lengua y Literatura española de la Universidad Central», el texto quedaba por entonces prácticamente letra muerta a la espera de la citada edición, como bien lo indicaba el conocido pedagogo Victoriano Fernández Ascarza [1870-1934] en su valioso Diccionario de legislación de primera enseñanza ${ }^{111}$.

Por ello, dos años más tarde, en marzo de 1922, César Silió [1865-1944], el nuevo Ministro de Instrucción Pública y Bellas Artes en un gobierno presidido por José Sánchez-Guerra [1859-1935] quien sustituía a Antonio Maura, intentaba reactivar el proceso «mandando designar un miembro de la Real Academia para participar en la preparación de la edición abreviada del Quijote» ${ }^{112}$.

Recordemos de paso que también fue Silió quien, para exaltar los valores patrióticos desde la Escuela, convocó en septiembre de 1921 un concurso para seleccionar una obra destinada a «dar a conocer a los nińos lo que es y representa Espańa y hacerla amar», obra que sería declarada libro «de texto y de lectura obligatoria en todas las Escuelas Nacionales» ${ }^{113}$, y que el mismo Silió decretó en octubre de 1921 que en todas las escuelas públicas debía colocarse

111. Victoriano Fernández Ascarza, Diccionario de legislación de primera enseñanza, op. cit., 1924, p. 709: «La edición abreviada oficial que aquí se promete no se ha publicado, y, en consecuencia, el Decreto no se puede cumplir».

112. «Real orden mandando designar un miembro de la Real Academia para participar en la preparación de la edición abreviada del Quijote», 10-III-1922, Boletín Oficial del Ministerio de Instrucción pública y Bellas Artes, Madrid, n² 23, 21-III-1922, p. 335.

113. "Real decreto convocando un concurso para elegir un libro destinado a dar a conocer a los niños lo que es y representa España», 9-IX-1921, Boletín Oficial del Ministerio de Instrucción Pública y Bellas Artes, Madrid, n 74, 16-IX-1921, pp. 1078-1079. El concurso resultaría desierto. Ver Alberto del Pozo Pardo, "El Libro de la Patria, un concurso escolar vacío, de matiz regeneracionista (1921-1923)», en J. Ruiz Berrio (Ed.), La educación en la España contemporánea. Cuestiones históricas. Libro homenaje a Ángeles Galino, Madrid, Sociedad Espańola de Pedagogía, 1985, pp. 195-202. 
«en sitio visible» un retrato del soberano reinante -o sea Alfonso XIII- como cabeza del «Poder moderador que representa a la unidad de la Patria» ${ }^{114}$.

En realidad, más interesante que el texto mismo del decreto de marzo de 1920, nos aparece la larga exposición del mismo que explicita y justifica el sentido de la presencia de la obra cervantina en el espacio escolar, volviéndose a inducir en su dimensión nacionalizadora, no sin constantes hipérboles sobre el autor y su obra:

La nación espańola tiene la inmensa fortuna de contar entre sus hijos a Miguel de Cervantes Saavedra, genio culminante de nuestra raza y autor del libro más inmortal y excelso que vieron los siglos. El Ingenioso Hidalgo Don Quijote de la Mancha es biblia profana de la Edad Moderna, arsenal copiosísimo que atesora sentencias, observaciones y verdades, donde el hombre de saber halla siempre la expresión adecuada de cuanto signifique postulados amplios y generales; el que tiene mediana cultura vastos horizontes de conocimientos que aún no posee; el que sólo adquirió las elementales nociones de la instrucción primaria, frases y razonamientos que presentan claras a su inteligencia las normas vulgares y corrientes de la vida cotidiana, y todos en general, el exuberante y riquísimo venero de nuestro espléndido idioma; pues de este libro sin par puede decirse, mejor que de ningún oro, que tiene tantos diamantes como dicciones.

\section{CERVANTES EN LA ESCUELA. ¿EL QUIJOTE AL ALCANCE DE LOS NIÑOS?}

Pero todos los pedagogos y todos los intelectuales no estaban totalmente a favor de una presencia directa del texto de Cervantes en las escuelas tal como se había promovido desde el Ministerio de Instrucción pública.

Ya en 1904, las reacciones ante la tentativa entonces fallida de Eduardo Vincenti de introducir la obligatoriedad de la lectura del Quijote en clase y de hacer de la obra de Cervantes (adaptada desde luego a un público escolar) un libro de texto fueron numerosas y en general contrarias, tanto en el seno de la corporación docente como en otros ámbitos. Se solía considerar, en efecto, que el texto cervantino se adecuaba muy poco o nada al entendimiento de los jóvenes alumnos. «Vaya, Sr. Vincenti, que por esta vez se ha equivocado usted», no dudaba en afirmar, por ejemplo, un artículo anónimo del Defensor del

114. Real orden, 4-X-1921, Boletín Oficial del Ministerio de Instrucción Pública y Bellas Artes, Madrid, n 85, 25-X-1921, p. 1265. 
Magisterio tras referirse a la proposición de Eduardo Vincenti en el Congreso de los Diputados ${ }^{115}$.

En El Magisterio Español, otro representante de la prensa pedagógica, Ildefonso Fernández y Sánchez [1843-1913], también colaborador de La Ilustración Católica y director de La Revista de Primera Enseñanza, tras afirmar que Vincenti, «sugestionado, como todos, por el entusiasmo nacional que reina en honor del Príncipe de los Ingenios, no ha meditado bien sobre las condiciones pedagógicas de una obra, cuya lectura, de provechísimo deleite para las inteligencias ya hechas, ofrece, sin embargo, [...] gravísimos inconvenientes para la niñez», señalaba, más allá de las incorrecciones gramaticales y los aspectos un tanto arcaicos del texto cervantino, «el daño moral que la lectura del Quijote puede producir a los niños, y singularmente en las niñas», por la «libertad de expresión, propia de los escritores del siglo XVII, que no se andaban con remilgos, ni empleaban eufemismos de ninguna clase para llamar las personas y las cosas con las palabras más crudas y desnudas, de un vocabulario que no encaja en nuestras costumbres, y que el decoro moderno aleja de los hogares en que se respeta la castidad y decencia de los corazones infantiles» ${ }^{116}$

Las críticas también afloraron en la prensa de información general. En el diario barcelonés La Vanguardia, el cronista Pedro Garrido resumía así en marzo de 1904 los argumentos de los adversarios de la presencia directa del Quijote en las aulas ${ }^{117}$ : el castellano manejado por Cervantes era arcaico y ya no se empleaba; hay en el texto escenas demasiado realistas que son poco edificantes y por lo tanto perjudiciales para los niños, ¡los cuales llegarían incluso a redactar las cartas familiares en lengua y estilo cervantinos! Existen muchos escritores, añadía el periodista, que pueden servir perfectamente de modelo a los alumnos, tales como Mariano José de Larra, Ramón de Mesonero Romanos, Severo Catalina, Pedro Antonio de Alarcón, Juan Valera, José María de Pereda y Benito Pérez Galdós, autores todos del siglo XIX a los que consideraba como «atildados y selectos».

Casi un año después, el escritor y catedrático de psicología Arturo Masriera [1860-1929] titulaba provocativa e irónicamente su artículo dedicado al

115. «La lectura», El Defensor del Magisterio, 25-III-1904, cit. por Josep Pallach, Els mestres publics i la reforma de l'ensenyament a Catalunya (1901-1908), Barcelona, Ediciones CEAC, 1978, p. 165.

116. Ildefonso Fernández y Sánchez, "De actualidad. El «Quijote» en la escuela», El Magisterio Español, Madrid, Año XXXVIII, n 2772, 23-III-1904, p. 163.

117. Pedro Garrido, "El Quijote en la escuela», La Vanguardia, Barcelona, 22-III-1904, cit. por Carme Riera, El Quijote desde el nacionalismo catalán, en torno al Tercer Centenario, op. cit., p. 209, n. 253. 
Quijote en El Diario de Barcelona "Que no lo lean», ya que «la juventud de un pueblo de mentalidad tan oblicua como el español corre grave riesgo al cobrar amor a un libro que ha de ser su mayor enemigo en el día de mañana» ${ }^{118}$.

Por lo contrario, Carmen García de Castro se declaraba totalmente partidaria de la implantación del Quijote como lectura obligatoria en las escuelas:

[...] Creo que en España, como en otras naciones, debiera implantarse la lectura del «Quijote». [...] Si a todos los hombres conviene su lectura, a los espańoles conviene doblemente. Escrito para los nińos espańoles parece este gran libro, donde tan clara y exactamente se pintan los defectos de nuestro pueblo ${ }^{119}$.

En la polémica en torno a "Cervantes y la escuela», agudizada naturalmente durante el año mismo del centenario, tomaron parte tanto los medios de comunicación como diversos colectivos e instituciones político-culturales. Varias entidades debatieron así de la cuestión que en realidad venía a ser la de la utilidad o no de la presencia de los autores «clásicos» en el ámbito escolar.

La Asociación provincial de maestros de las Escuelas públicas de Barcelona convocó incluso un concurso sobre el tema «¿Es conveniente declarar $E l$ Quijote como texto obligatorio de lectura para uso de las Escuelas de primera enseñanza?». En El Quijote en las Escuelas, trabajo premiado en el certamen, Antonio Cremades y Bernal ${ }^{120}$, maestro de escuela pública, consideraba, tras haber precisado las condiciones y cualidades del libro de lectura (verdad y decencia, sencillez y claridad), que la obra cervantina no resultaba adecuada para ello, "pues su fin no corresponde al de la educación de la nińez», añadiendo que «su intencionalidad se halla muy distante del objeto de la lectura» y que

118. Arturo Masriera, "Que no lo lean», El Diario de Barcelona, Barcelona, n 46, 23-II1905, pp. 2175-2177.

119. Carmen García de Castro, El Quijote en la escuela. Desarrollo del tema: enseñanzas literarias y pedagógicas contenidas en el Quijote. Premiado en el Certamen que con motivo del tercer Centenario de la publicación de "El Ingenioso Hidalgo Don Quixote de la Mancha" se celebró en Málaga por los centros docentes, en Mayo de MCMV, Écija, Imprenta Reyes, 1906, pp. 35-36.

120. Antonio Cremades y Bernal, El Quijote en las Escuelas. Estudio premiado por la Asociación provincial de maestros de las Escuelas públicas de Barcelona, en el Certamen literario con que conmemoran la tercera fecha centenaria de "El Quijote», Valencia, Imp. de Vicente Ferrandis, 1905, 48 p. El mismo también publicó sus Comentarios sobre frases de «El Quijote» que tienen relación con la educación e instrucción públicas. Tema que obtuvo el primer premio en el certamen nacional celebrado por la Asociación provincial de maestros públicos de Barcelona para solemnizar el III centenario de la obra inmortal de Cervantes, Valencia, Imp. Domenech y Trincher, 1906, X-39 p. 
«la desnudez de su lenguaje se opone a la moral de los niños». Como Garrido, Cremades y Bernal opinaba que el lenguaje utilizado por Cervantes en el Quijote era anticuado e incluía "palabras de bajo significado». Según él, la novela «representa una historia que abunda en mentiras e inverosimilitudes» $y$ «sus razonamientos son superiores a la comprensión de un niño». Finalmente, tampoco le parecía que El Quijote para Niños, o sea la adaptación escolar, respondía a las cualidades pedagógicas del libro de lectura.

Entre los colectivos contrarios a la lectura del Quijote en clase figuraban los eclesiásticos, naturalmente proclives a que los alumnos leyeran otros textos considerados como más «morales» ${ }^{121}$. Para el jesuita Juan Mir Noguera [18401917], quien participó no obstante en varios de los actos organizados durante el año del centenario, «los Diálogos de Fray Juan de Pineda atesoran más riqueza de lenguaje, más viveza de locuciones, más preciosidad de modismos, más fondo, en fin, de frases y vocablos que todas las obras cervantinas acompañadas del inmortal Quijote» ${ }^{122}$. En mayo de 1905, un periodista del diario republicano El País, J. Fernández, aludía también al propósito a la conferencia pronunciada en Sevilla en 1899 por otro eclesiástico erigido en nuevo inquisidor, Manuel Sánchez de Castro, en la cual éste pedía nada menos que «la cremación de Don Quijote» ${ }^{123}$.

Pero la lectura del Quijote en clase acabó imponiéndose, pese a todas esas críticas o al menos reticencias de unos y otros. Según una crónica del diario $E l$ Pais que intentaba esbozar un balance del centenario, habían triunfado quienes consideraban que «El Quijote es un texto educador, una joya pedagógica y no tanto porque es un monumento clásico de la lengua castellana en el que cristalizó el idioma, fijó para siempre sus giros, su sintaxis, su léxico usual, sino porque principalmente corrige, fustiga y combate las dos tendencias nacionales funestas, el quijotismo y el pancismo, comunes a todo el género humano pero dominantes en la estirpe española, entregada por iguales partes a las exaltaciones irracionales del idealismo y a las groseras concupiscencias materialistas» ${ }^{124}$.

Algunos escritores prestigiosos intervinieron también en el debate por aquellas fechas. Para Miguel de Unamuno, en una conferencia pronunciada

121. Ver Manuel de Castro Alonso, La moralidad del Quijote, Valladolid, Tip. de J. M. de la Cuesta, 1906, 173 p.

122. Juan Mir Noguera, El Centenario quijotesco, Madrid, Sáenz de Jubera, Hermanos, Editores, 1905, cit. por Carme Riera, op. cit., p. 211.

123. Manuel Sánchez de Castro, La Cremación de Don Quijote, Sevilla, Escuela tipográfica Salesiana, 1899, 38 p.; J. Fernández, «La cremación del Quijote», El Pais, Madrid, 24-V-1905, cit. por Carme Riera, op. cit., p. 211.

124. El Pais, Madrid, 8-V-1905, cit. por Carme Riera, op. cit., p. 211. 
en Bilbao en agosto de 1905, la lectura escolar de los autores «clásicos» -incluyendo naturalmente a Cervantes pero no de forma exclusiva- no podía resultar sino beneficiosa para los jóvenes:

A los niños se les debe dar a leer [...] las mismas cosas que los mayores leen, sin más que bien escogidas. ¿Qué inconvenientes hay en que los niños lean en España a Cervantes, a Calderón, a Santa Teresa, a Fray Luis de León, a Jorge Manrique, a Quintana? Se dirá que exceden de su alcance. [...] Hay que dar oro puro, aunque sea en proporciones modestas, y con ese oro puro del arte excitar la imaginación infantil ${ }^{125}$.

Lo mismo opinaba la novelista Emilia Pardo Bazán [1851-1921], quien en el marco de un homenaje poético al recién fallecido José María Gabriel y Galán [1870-1905] realizado en Salamanca ese mismo año de 1905 exclamaba con fuerza: «hagamos que nuestros escolares se aficionen a la lectura del Quijote» ${ }^{126}$.

Como respuesta a la medida ministerial de 1912, el conocido pedagogo Ezequiel Solana, quien ya había participado en las conmemoraciones del tercer centenario con un Homenaje a Cervantes ${ }^{127}$, publicó en 1913 su Cervantes educador, que no era una nueva versión reducida del Quijote sino una presentación alfabética de diversos temas (tales como la ambición, el amor fraternal, la higiene, los maestros de escuela, la popularidad, las relaciones de señores y criados o la vida pastoril) ilustrados con fragmentos cervantinos ${ }^{128}$. Se trataba, pues, en realidad de una apasionada defensa de la presencia del Quijote en clase:

125. Miguel de Unamuno, «La enseñanza de la Gramática», Boletín de la Institución Libre de Enseñanza, Madrid, n 561, 1906, p. 360. Ver también su artículo «El Quijote de los niños» publicado en «Los lunes de El Imparcial», 13-XII-1915.

126. Opinión recogida en José María Hernández Díaz, José Antonio Bonilla Hernández, El Quijote en la escuela. Exposición IV centenario, op. cit., p. 16.

127. Ezequiel Solana, Homenaje a Cervantes, en el tercer Centenario del "Quijote», Madrid, El Magisterio Espańol, 1905, 64 p. Sobre Solana, ver la nota biográfica de Rafael M. Sanz de Diego en Buenaventura Delgado Criado (Ed.), Historia de la Educación en España y América. Volumen 3. La Educación en la España contemporánea (1789-1975), Madrid, Ediciones SM-Morata, 1994, pp. 637-638.

128. Ezequiel Solana, Cervantes educador. Colección de trozos de obras cervantinas, dispuestos para ser leidos en las escuelas. Obra premiada en público certamen, Madrid, Imp. de «El Magisterio Espańol», 1913, 126 p. Ver Alejandro Tiana Ferrer, «Ediciones infantiles y lectura escolar del Quijote. Una mirada histórica», op. cit., pp. 217-218. 
El mérito del Quijote, como obra de moral, como libro de educación, excede a todo encarecimiento. [...] La muchedumbre y variedad de reflexiones, de sentencias y discursos que se encuentran en el Quijote sobre casi todos los asuntos y ocurrencias de la vida, esparcidos con tanta oportunidad como abundancia, justifican la admiración y el aprecio con que han mirado este portentoso libro literatos, filósofos y moralistas de diversos tiempos y naciones, considerándolo como el más adecuado para enseñar a la juventud el camino del honor, de la caballerosidad y de la hidalguía ${ }^{129}$.

El autor precisaba la forma en que su libro podría emplearse en clase y las distintas modalidades de su uso entre los alumnos, tanto para enseñar a leer a los más jóvenes como para realizar ejercicios de idioma y de dictado con los más avanzados, y también «para despertar nobles sentimientos, para adquirir el buen gusto y para formar el carácter» ${ }^{130}$.

Tras la publicación del decreto de Natalio Rivas en 1920, volvió a arreciar la polémica. En un artículo publicado entonces en el diario La Libertad, el escritor Antonio Zozaya [1859-1940] afirmaba rotundamente que «el Quijote no es lectura para párvulos ni para adolescentes» y que "en la escuela no hacen falta Don Quijote ni Hamlet» ${ }^{131}$.

El ya célebre filósofo y ensayista José Ortega y Gasset [1883-1955], hijo de José Ortega Munilla y sobrino de Rafael Gasset, que ya se había interesado en el Quijote en sus Meditaciones del "Quijote» (1914) ${ }^{132}$, partió de tales afirmaciones para elaborar un largo ensayo pedagógico titulado precisamente «El Quijote en la escuela», publicado en el diario El Sol a partir del 16 de marzo de 1920 e incluido posteriormente en el tomo tercero de su recopilación de artículos titulada El Espectador, lo que muestra la importancia alcanzada por el debate ${ }^{133}$. Llegando a considerar el decreto de Natalio Rivas como un verdadero "desatino», Ortega manifestaba su acuerdo con la postura de Zozaya, discrepando no obstante en los motivos por los que se oponía a la medida ministerial. Ortega fundamentaba en efecto su oposición al decreto en el concepto de vida infantil que sustentaba su idea de la educación:

129. Ezequiel Solana, Cervantes, educador, op. cit., pp. 9-10.

130. Ibid., pp. 21-22. Ver también Acisclo Muñiz Vigo, Cervantes en la escuela, Burgos, Hijos de Rodríguez, 1913, 284 p.

131. Antonio Zozaya, "Aprendamos a vivir», La Libertad, Madrid, 12-III-1920, p. 1.

132. Ver Anthony Close, La concepción romántica del Quijote, op. cit., pp. 208-223.

133. José Ortega y Gasset, «El Quijote en la escuela», en Obras completas, t. II, Madrid, Taurus-Fundación Ortega y Gasset, 2004, pp. 401-430. 
[...] Claro es que si a los niños pudiera enseñarse todo, también habría que enseñarles eso. Pero la cuestión está en que la capacidad receptiva del niño y la docente del maestro son muy limitadas en volumen, en calidad y en tiempo. El problema de la educación es siempre un problema de eliminación, y el problema de la educación elemental es el problema de la educación esencial ${ }^{134}$.

Pero la polémica no iba a cesar en 1920. Por ejemplo, en 1927, con ocasión de la celebración de la segunda fiesta del libro, Luis Redonet y López Dóriga [1875-1972] pronunció un discurso en la Real Academia de Ciencias Morales y Políticas en el que, aludiendo al decreto de marzo de 1920, afirmaba su frontal oposición a la medida ministerial con argumentos ya aducidos anteriormente en torno a la inadecuación del texto cervantino para jóvenes alumnos:

El Quijote es inadecuado para los niños. ¿Por su fraseología cruda y realista? [...] No es [...] por su fraseología, inmoral nunca, ni de mal gusto entonces, por lo que juzgo inadecuado para niños El Quijote, sino porque escapa al alcance de su inteligencia y porque causará en ellos profundo y dañoso aburrimiento ${ }^{135}$.

Y casi diez años más tarde, en 1936, el lingüista Salvador Fernández Ramírez [1896-1983], miembro del Centro de Estudios Históricos, seguía rechazando asimismo la utilización escolar del Quijote, valiéndose de los análisis de Ortega y calificando de «superstición [...] pervertida [...] la que emanó de esferas oficiales instaurando por decreto la lectura del Quijote en la escuela» ${ }^{136}, \mathrm{y}$ proponiendo otros modelos literarios como «lecturas preferentes» destinadas a los alumnos:

Sería algo desorbitado y abusivo pretender que el nińo pudiese encadenarse a determinadas lecturas. Refiriéndose al adolescente, dice Sprangler que «las grandes novelas que tenemos son demasiado sublimes para la edad de la furia de

134. Ibid., p. 402.

135. Luis Redonet y López Dóriga, El amor al libro. Discurso leído [...] en la Real Academia de Ciencias Morales y Políticas, Madrid, Imprenta de la Viuda e Hijos de J. Ratés, 1927, $30 \mathrm{p}$.

136. Salvador Fernández Ramírez, «La enseñanza de la Gramática y de la Literatura», en Libro-Guía del maestro. Los problemas y los órganos de la enseñanza primaria. Didáctica de todas las materias. Obras alrededor de la escuela. Bibliografia, Madrid, Espasa-Calpe, S.A., 1936, p. 378 . 
lectura». No por motivos diferentes recusa Ortega y Gasset el Quijote en la escuela, como obra de espíritu demasiado moderno, totalmente extrańa al alma antigua y primitiva del niño. Se deben presentar, por consiguiente, al escolar como lecturas preferentes los grandes ciclos épicos de la antigüedad y de la Edad Media y gran parte del material mítico que nos han legado los pueblos clásicos ${ }^{137}$.

No obstante, para responder a la demanda en tal sentido, las editoriales y las librerías escolares seguían proponiendo en los años veinte y treinta del siglo XX varias ediciones escolares del Quijote, siempre consideradas como libros de lectura ${ }^{138}$. Y un significativo grabado alegórico incluido en un catálogo de la Editorial Luis Vives, afincada en Zaragoza, mostraba en 1935 a un maestro bajando, ante el entusiasmo de los jóvenes alumnos agrupados a su alrededor, una estatua de Don Quijote y Sancho Panza de la estantería donde estaba situada junto a un busto de Cervantes, contribuyendo por lo tanto, tal como rezaba el pie de ilustración, a poner concreta y materialmente la obra de Cervantes «iAl alcance de los niños!» ${ }^{139}$.

\section{CONCLUSIÓN. EL DÍA DEL LIBRO (I926)}

Prueba de la resistencia en considerar el Quijote como lectura escolar son los resultados de una encuesta realizada en marzo de 1920, inmediatamente tras la publicación del ya mencionado decreto de Natalio Rivas, por el Inspector escolar Antonio J. Onieva entre 924 alumnos, de los cuales 398 (o sea el $43 \%$ ) eligieron el Quijote y 520 optaron por otros libros (Corazón de Edmondo de Amicis, Europa de José Dalmáu Carles y Juanito de L. A. Parravicini) ${ }^{140}$.

Pero al mismo tiempo se demostraba la no desdeńable presencia del Quijote en clase. Y las constantes reediciones de Quijotes escolares a principios del

137. Ibid., p. 376.

138. Librería de la Infancia Germán Arnáiz, Catálogo ilustrado. Material de enseñanza, objetos de escritorio, artículos de dibujo, libros escolares, literarios, premios, Madrid, Librería de la Infancia, 1926, p. 131; Catálogo ilustrado de la Librería Escolar Hijos de Antonio Pérez, Madrid, Hijos de Antonio Pérez, 1930, p. 133.

139. Catálogo. Primera enseñanza. Segunda enseñanza. Enseñanza comercial. Libros de premio. Libros para educadores, Zaragoza, Editorial Luis Vives, 1935, p. 51.

140. Antonio J. Onieva, «Lo que los niños piensan del Quijote», El Sol, Madrid, n 829, 25-III-1920, p. 12, cit. por María del Mar del Pozo Andrés, Currículum e identidad nacional, op. cit., p. 195, n. 29. 
siglo XX pueden dar a pensar razonablemente que de una forma u otra las disposiciones oficiales llegaron a ser cumplidas y que efectivamente el Quijote penetró en las aulas y en la práctica docente tal como lo prescribía el Ministerio. El examen de diarios de clase de los años veinte y treinta del siglo XX también evidencia que la lectura del Quijote constituía una actividad educativa que se desarrollaba todos los días de la semana ${ }^{141}$.

Dentro de la inmensa bibliografía de ediciones del Quijote, una categoría aparte la forman, pues, los Quijotes escolares, que se publicaron prácticamente de forma ininterrumpida desde mediados del siglo XIX, adaptados para su uso escolar (bien abreviados, bien corregidos para salvar en la medida de lo posible las dificultades del texto, muchas veces ambas cosas), dentro de las actividades de lectura, eje vertebrador de la enseñanza primaria.

Pero la presencia del Quijote en el ámbito escolar puede rastrearse también, bajo la forma de extractos, en los libros escolares dedicados a la enseńanza de refranes, máximas y sentencias morales, lo que sucedía de hecho desde el siglo XIX ${ }^{142}$. De una forma u otra, el Quijote había ya encontrado su espacio en la cultura escolar pero a principios del siglo XX cobra verdadera relevancia en el currículum escolar la lectura directa de la obra en versiones adecuadas a tal objeto.

¿Había calado de esa forma el proyecto nacionalizador que pretendía hacer del Quijote el símbolo de la identidad nacional? Durante bastante tiempo, se buscó cómo implantar una fiesta permanente que pudiera representar el papel simbólico que se le quería otorgar a Cervantes y al Quijote. Tras el tercer centenario, el Ayuntamiento madrileño -apuntemos que el siempre activo y omnipresente Eduardo Vincenti volvió a ser Alcalde de la Villa y Corte del 19 de junio al 2 de noviembre de 1913- pidió así durante varios años que el Estado estableciera una «Fiesta del Idioma castellano» y la declarara «fiesta nacional».

141. Ma del Mar del Pozo Andrés, Sara Ramos Zamora, «El cuaderno de clase como instrumento de acreditación de saberes escolares y control de la labor docente», en $X I$ Coloquio Nacional de Historia de la Educación. La acreditación de saberes y competencias. Perspectiva histórica. Oviedo, 12-15 de junio de 2001, Oviedo, Sociedad Española de Historia de la Educación y Departamento de Ciencias de la Educación de la Universidad de Oviedo, 2001, pp. 491-492.

142. Por ejemplo, Colección selecta de moral y elocuencia en prosa y verso, entresacada de los mejores escritores españoles para servir de texto de lectura en las escuelas primarias, por una sociedad de padres de familia, $9^{a}$ ed., Obra aprobada por el gobierno, Barcelona, Librería de la Sra. Viuda e Hijo de Sierra, 1854, pp. 216-224. 
Culminación de este proceso y de tal demanda sería la creación en febrero de 1926, durante la dictadura de Primo de Rivera pues, del Día del Libro, «en la perdurable fecha del natalicio del inmortal Cervantes», siguiendo así con la exaltación patriótica de la lectura y de la lengua castellana en torno a la figura de Cervantes:

El día 7 de octubre de todos los ańos se conmemorará la fecha del natalicio del príncipe de las letras españolas, Miguel de Cervantes Saavedra, celebrando una fiesta dedicada al libro español ${ }^{143}$.

143. Real Decreto, 6-II-1926, Gaceta de Madrid, 9-II-1926. Por otro decreto de 7-IX1930, se trasladó la fiesta del libro al día 23 de abril, «fecha cierta de aniversario de la muerte de Cervantes». Ver Fernando Cendán Pazos, La Fiesta del Libro en España. Crónica y miscelánea, Madrid, Fundación Germán Sánchez Ruipérez (Biblioteca del Libro), 1989, 293 p. 